\title{
Acute depletion of activated memory $B$ cells involves the PD-1 pathway in rapidly progressing SIV-infected macaques
}

\author{
Kehmia Titanji,1,2 Vijayakumar Velu,, ${ }^{1,2}$ Lakshmi Chennareddi,1,2 Matam Vijay-Kumar, ${ }^{3}$ \\ Andrew T. Gewirtz, ${ }^{3}$ Gordon J. Freeman, ${ }^{4}$ and Rama R. Amara ${ }^{1,2}$

\begin{abstract}
1Department of Microbiology and Immunology, Emory Vaccine Center, Emory University School of Medicine, Atlanta, Georgia, USA. 2Division of Microbiology and Immunology, Yerkes National Primate Research Center, Emory University, Atlanta, Georgia, USA. ${ }^{3}$ Department of Pathology, Emory University School of Medicine, Atlanta, Georgia, USA. ${ }^{4}$ Department of Medical Oncology, Dana-Farber Cancer Institute, Department of Medicine, Harvard Medical School, Boston, Massachusetts, USA.
\end{abstract}

\begin{abstract}
Rapid progression to AIDS is a significant problem, especially in developing countries, where the majority of HIV-infected individuals reside. As rapid disease progression is also frequently observed in SIV-infected macaques, they represent a valuable tool to investigate the pathogenesis of this condition in humans. Here, we have shown that pathogenic SIV infection in rhesus macaques resulted in a rapid depletion (as early as week 2) of activated memory $B\left(\mathrm{CD}^{-} 1^{-} \mathrm{CD} 27^{+} ; \mathrm{mB}_{\mathrm{Act}}\right)$ cells that was strongly associated with rapid disease progression. This depletion was progressive and sustained in rapid progressors, but less severe and transient in typical progressors. Because of the rapid and sustained depletion of $\mathbf{m B}_{\text {Act }}$ cells, rapid progressors failed to develop SIV-specific Ab responses, showed a decline in non-SIV-specific Ab titers, and succumbed faster to intestinal bacterial infections. Depletion of $\mathrm{mB}_{\text {Act }}$ cells was strongly associated with preferential depletion of $\mathbf{m B}_{\text {Act }}$ cells expressing programmed death-1 (PD-1), and in vitro blockade of PD-1 improved their survival. Furthermore, in vivo PD-1 blockade in SIV-infected macaques enhanced $\mathrm{Ab}$ responses to non-SIV as well as SIV Ags. Our results identify depletion of $\mathrm{mB}_{\mathrm{Act}}$ cells as a very early predictor of rapid disease progression in pathogenic SIV infection and suggest an important role for the PD-1 pathway in depletion of $\mathrm{mB}_{\mathrm{Act}}$ cells and impaired humoral immune responses in SIV-infected macaques.
\end{abstract}

\section{Introduction}

The pathogenesis of rapid progression to AIDS following HIV-1 infection remains poorly understood, despite more than 2 decades of intensive study. Rapid disease progression has been substantially curbed by the advent of highly active antiretroviral therapy (HAART) in developed countries, but it remains a significant problem in less developed regions of the world, where HAART use is not as widespread and where the majority of HIV-infected individuals live $(1,2)$. The mechanisms underlying differences in rate of disease progression are thought to involve both viral and host immunological factors $(3,4)$. A growing body of evidence also suggests that intense chronic systemic immune activation may be the main cause of rapid disease progression (5-7). While the timing of disease stages is shorter in rhesus macaques (RMs) compared with humans, the former presents an invaluable tool in evaluating pathogenesis of rapid disease progression. Rapid progressor humans develop clinical AIDS within 2-5 years of initial infection, compared with approximately 10 years in typical progressors (8); similarly, rapid progressor RMs succumb to AIDS-related illness within 6 months of infection compared with approximately 2-3 years in typical progressors (9).

Previous studies in humans and RMs suggested a role for general $\mathrm{B}$ cell dysfunction in rapid disease progression, with some earlier studies showing associations among depletion of circulating $B$ cells, low $\mathrm{Ab}$ responses to nonviral Ags, and rapid disease progres-

Conflict of interest: G.J. Freeman has patents and receives patent royalties on the PD-1 pathway.

Citation for this article: J Clin Invest. 2010;120(11):3878-3890. doi:10.1172/JCI43271. sion $(8,9)$. Loss of total memory B cells was previously shown to be an important pathogenic mechanism in viremic HIV-infected individuals, leading to impaired HIV-specific and non-HIV-specific humoral immune responses (10-13). A recent study of acute SIV infection in RMs also described a generalized loss of total memory B cells as an important factor in B cell dysfunction (14). Although these previous studies suggest an important role for general B cell dysfunction in disease pathogenesis, the B cell compartment of rapidly progressing animals has not been thoroughly characterized. The association between specific B cell subset defects and rapid disease progression in SIV infection is also not well understood.

The mechanism of $\mathrm{B}$ cell depletion during HIV/SIV infection is not completely understood, although a significant role for the Fas pathway in B cell depletion during HIV infection has been demonstrated. Programmed death-1 (PD-1) has recently emerged as an important immunoreceptor involved in both SIV and HIV pathogenesis, influencing $\mathrm{T}$ and $\mathrm{B}$ cell exhaustion (15-19). Although PD-1 has been previously shown to regulate B cell survival in mice (20), very little is known about its role in B cell survival during HIV/SIV infection. Here, we sought to thoroughly characterize the B cell compartment of RMs with different rates of disease progression to determine the role, if any, of B cell dysfunction and immune activation in rapid disease progression. We also investigated the role of the PD-1 pathway in B cell dysfunction during SIV infection in vitro and in vivo. To correlate our immunological findings with clinical changes occurring in the SIV-infected animals, we also followed the incidence of non-SIV infections. In addition, we compared the B cell compartments of animals with pathogenic (RMs) and nonpathogenic (sooty mangabeys; SMs) SIV infections to further understand 
the role of $\mathrm{B}$ cell defects in pathogenesis and disease progression. Our results identified the loss of activated memory B $\left(\mathrm{mB}_{\text {Act }}\right)$ cells as an early predictor of rapid disease progression in SIV-infected RMs and suggest an important role for the PD- 1 pathway in $\mathrm{mB}_{\text {Act }}$ cell depletion in rapidly progressing SIV infection.

\section{Results}

Identification of 4 distinct $B$ cell subsets, with differential surface CD21 and CD27 expression, in RM peripheral blood. CD27 has long been used as a unique marker for human memory B cells, but with the discovery of CD27- memory B cells $(21,22)$, it is becoming clearer that the memory $\mathrm{B}$ cell compartment is a heterogeneous population consisting of both $\mathrm{CD}_{27}{ }^{+}$and $\mathrm{CD} 27^{-}$subsets. We therefore sought to characterize the RM B cell compartment in a manner similar to that described for peripheral B cells of HIV-infected humans (22), using a combination of CD21 (also known as complement receptor 2; part of the $\mathrm{BCR}$ complex and costimulatory for $\mathrm{B}$ cells) and CD27. We identified 4 distinct $B$ cell subsets in peripheral blood of healthy RMs: naive $\left(\mathrm{CD} 21^{+} \mathrm{CD} 27^{-}\right)$, resting memory $\left(\mathrm{CD} 21^{\text {int }} \mathrm{CD} 27^{\text {int }}\right), \mathrm{mB}_{\text {Act }}\left(\mathrm{CD} 21^{-} \mathrm{CD} 27^{+}\right)$, and unconventional or tissue memory (CD21-CD27-) (Figure 1A and refs. 22, 23). CD20 expression (based on MFI) was higher on $\mathrm{mB}_{\text {Act }}$ and tissue memory $\mathrm{B}$ cells than on naive and resting memory cells $(P<0.001$; Figure $1 \mathrm{~B})$. Naive $B$ and $\mathrm{mB}_{\mathrm{Act}}$ cells were the majority subsets, each making up approximately $38 \%$ of total B cells, followed by tissue $(\leq 16 \%)$ and resting $(\leq 8 \%)$ memory B cells (Figure $1 \mathrm{C})$. To further confirm the identity of tissue memory B cells, we examined the expression of $\mathrm{CD} 21$ and $\mathrm{CD} 27$ on CD20 ${ }^{+}$cells in various tissues of uninfected animals and found that these were indeed the majority memory $\mathrm{B}$ cell subset present in the tissues (Supplemental Figure 1; supplemental material available online with this article; doi:10.1172/ JCI43271DS1). We also examined B cell subset distribution in 15 healthy HIV- humans and found that, in contrast to RMs, resting memory B cells were the majority memory B cell subset, with the combined activated and tissue memory subsets making up less than $10 \%$ of the total B cell population (Figure 1D).

We further characterized the B cell subsets by analyzing expression of the B cell-relevant activation and differentiation markers CD40, CD80, CD95, and CD11c (Figure 1E). CD40, one of the costimulatory receptors of the TNF receptor family, is an important modulator of B cell responses. Virtually all naive and resting memory B cells - and greater than $70 \%$ of tissue memory B cells - were CD 40 hi, whereas the majority (>70\%) of $\mathrm{mB}_{\text {Act }}$ cells were CD $40^{\text {int }}$. CD80 (also known as B7.1, binds to CD28 and provides costimulatory signals to $\mathrm{T}$ cells) expression is a marker of $\mathrm{B}$ cell activation. CD80 was previously shown to identify a specific subpopulation of pre- $\mathrm{mB}_{\text {Act }}$ cells that responds rapidly (24), secretes particularly large amounts of class-switched Igs, and efficiently presents Ag to and activate $T$ cells (25). Consistent with this function, the $\mathrm{mB}_{\text {Act }}$ cells expressed the highest levels of CD80. In addition to their roles as activation markers, expression of CD95 (death receptor; also known as Fas) and CD11c was previously identified as part of a signature profile for a new subset of tissue-based CD27- memory B cells (26). mB $_{\text {Act }}$ cells expressed the most CD95 and CD11c, closely followed by resting memory B cells. CD11c was only expressed on $\mathrm{mB}_{\text {Act }}$ and tissue memory $\mathrm{B}$ cells, with naive $\mathrm{B}$ cells expressing negligible amounts of CD80, CD95, and CD11c (Figure 1E). Thus, based on their surface marker expression, $\mathrm{mB}_{\text {Act }}$ cells represent an effector-type B cell subset that is activated and primed to secrete large amounts of $\mathrm{Ab}$ and to efficiently function as APCs.
SIV infection leads to rapid depletion of peripheral blood $m B_{\text {Act }}$ cells. One of the first observable changes occurring in the B cell compartment following HIV and SIV infections is a marked decrease in the number of total B cells $(8,9,11,27)$. However, which specific $B$ cell subsets are depleted, the kinetics of depletion, and association with disease progression in SIV infection of RMs are not well defined. We sought to characterize these parameters in 2 groups of RMs with distinct rates of disease progression. We classified animals that developed AIDS and were euthanized within 6 months of infection as rapid progressors, and the rest of the animals as typical progressors. We found that as early as 2 weeks following SIV infection, total B cells in blood were severely depleted in terms of both proportion and absolute number, regardless of rate of disease progression $(P<0.001$ and $P<0.0001$, rapid and typical, respectively; Figure 2, A and B). A rebound in total B cell numbers occurred by week 12 post infection in both rapid and typical progressors, but remained significantly different from preinfection levels $(P<0.0001)$. Consistent with previous reports of generalized memory B cell loss in HIV and SIV infections $(11,12,28)$, we also observed decreased proportions of all memory B cell subsets, particularly in the rapid progressors (Figure 2C). Upon further analysis of the memory B cell subsets in both groups of animals, we observed a striking preferential depletion of $\mathrm{mB}_{\text {Act }}$ cells by 2 weeks of infection (Figure 2C). This loss was sustained in the rapid progressors who had lost $82 \%$ of their $\mathrm{mB}_{\text {Act }}$ cells by week 12 post infection; in contrast, the drop in $\mathrm{mB}_{\text {Act }}$ cell proportions in typical progressors was transient and returned to preinfection levels by week 12 (Figure 2D). A significant decrease in proportions of resting memory B cells was also observed in both groups. Interestingly, we observed an apparent increase in the proportion of naive B cells by week 12 post infection in rapid progressors, but not in typical progressors. We also analyzed the absolute counts of the individual B cells subsets and found similar patterns except for a few differences (Supplemental Figure 2A). The numbers of naive B cells dipped at week 2 in both groups, but were restored to preinfection levels by week 12 in the rapid, but not typical, progressors. In addition, we observed significant decreases in the absolute number of tissue memory B cells in both groups post infection.

Early depletion of $m B_{\text {Act }}$ cells is associated with higher set-point viremia and rapid disease progression. The striking contrast in degree of $\mathrm{mB}_{\text {Act }}$ cell depletion between rapid and typical progressors prompted us to investigate whether this depletion had any significance for setpoint viremia and disease progression. Multiple factors measured during chronic infection, including plasma viral load (29), total $\mathrm{CD}^{+} \mathrm{T}$ cell depletion in gut (30), and total central memory CD4 ${ }^{+}$ $\mathrm{T}$ cell $\left(\mathrm{T}_{\mathrm{CM}}\right.$ cell; $\left.\mathrm{CD} 28^{+} \mathrm{CD}^{+} 5^{+}\right)$depletion in blood $(31,32)$, have been suggested to influence disease progression in both RMs and humans. We therefore analyzed all 3 parameters in an attempt to determine their relation to rapid disease progression in RMs. Rapid and typical progressors had similar peak viral loads (week 2); however, set-point viral load (week 12) was more than 1 log greater in the rapid than in the typical progressors $(P<0.0001$; Figure $3 \mathrm{~A})$.

By 2 weeks post SIV infection, the rapid progressors had significantly lower proportions of $\mathrm{mB}_{\text {Act }}$ cells compared with the typical progressors $(P<0.0001$; Figure $3 C)$. By 12 weeks post infection, the $\mathrm{mB}_{\text {Act }}$ cells were further depleted in the rapid, but not typical, progressors, resulting in even greater difference between the groups $(P<0.0001)$. We performed correlation analyses in order to further understand the relationship between early depletion of $\mathrm{mB}_{\text {Act }}$ cells and set-point viremia, and observed moderately significant inverse 
A
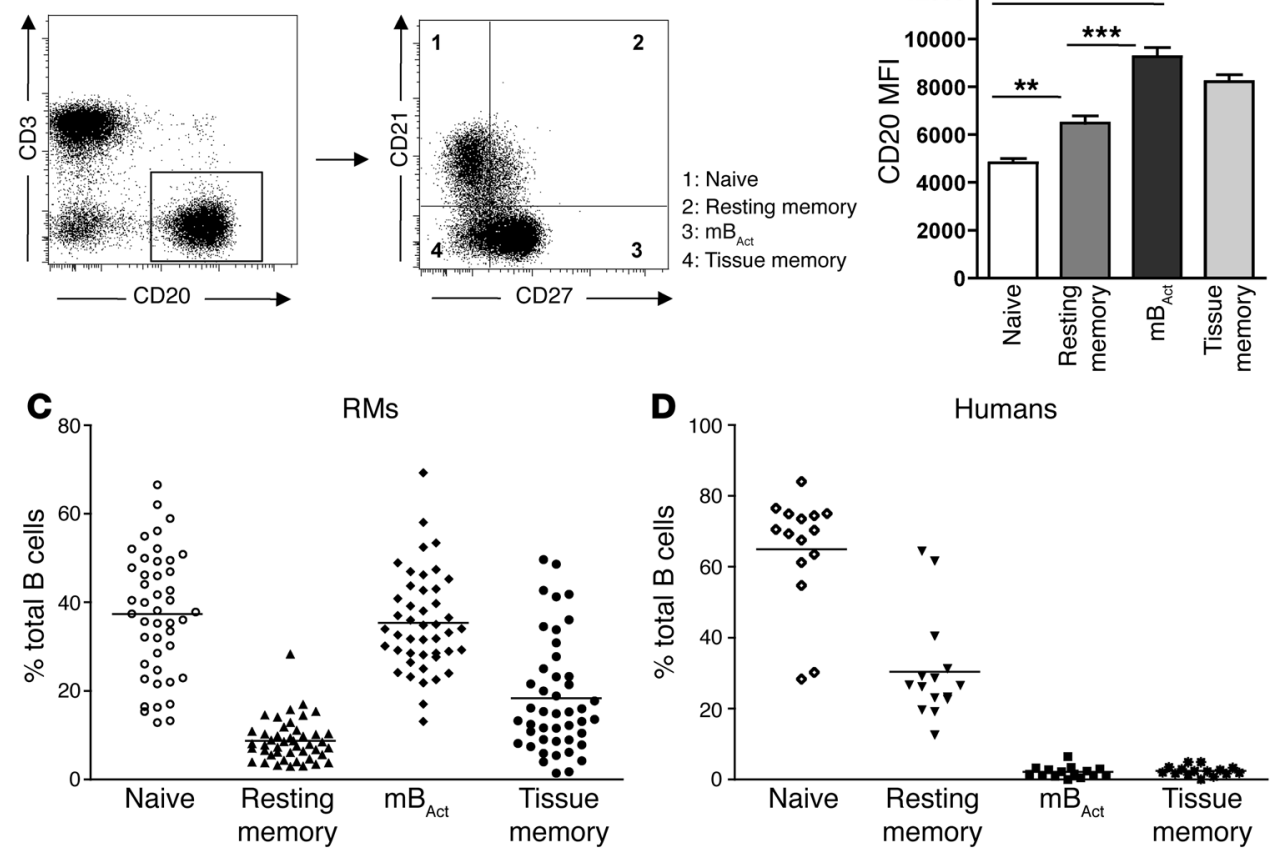

B

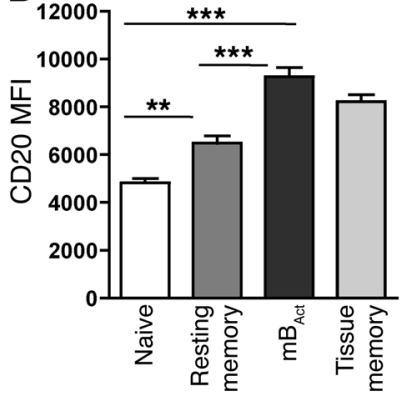

Humans
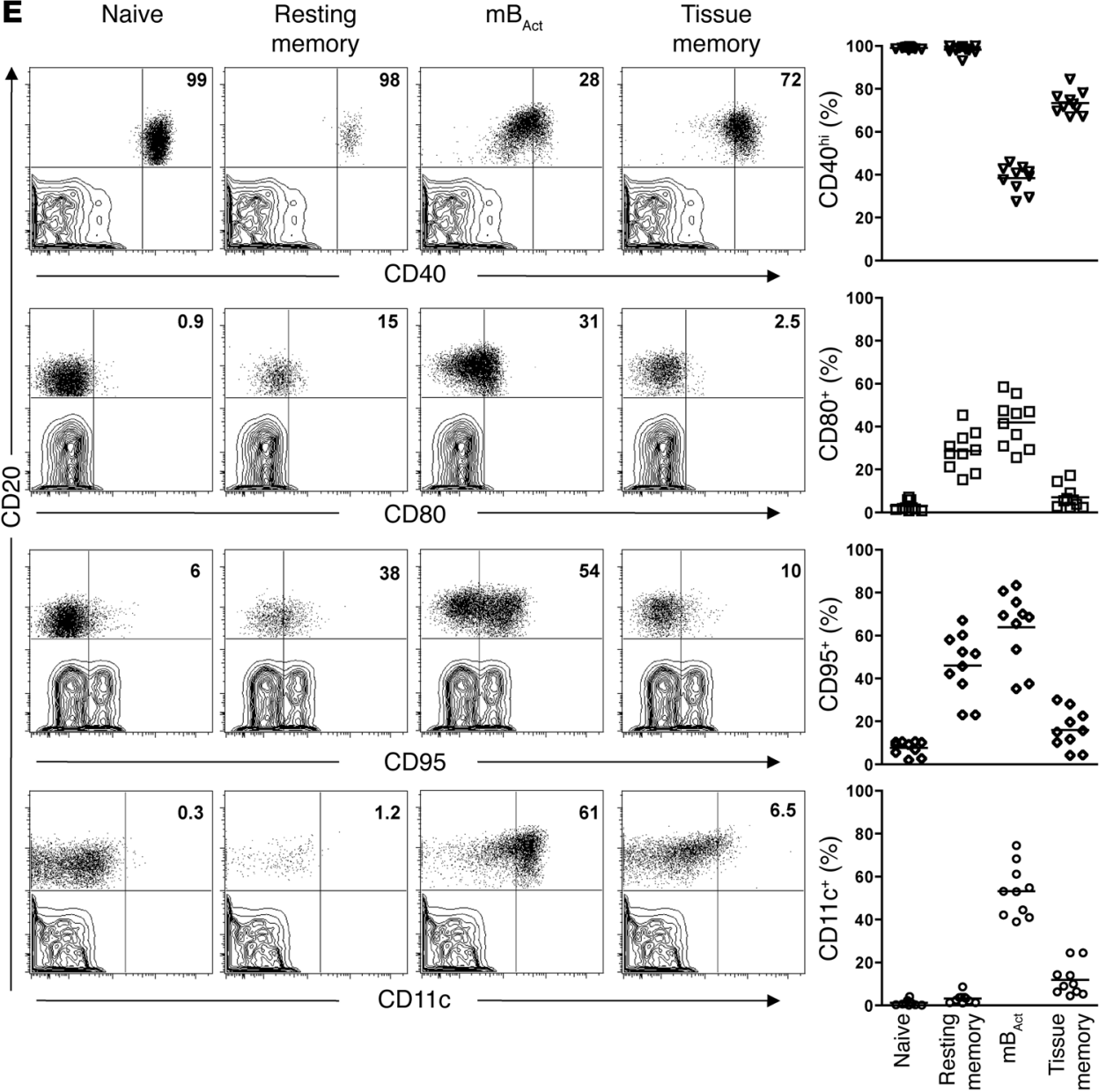

Figure 1

Identification of 4 phenotypically distinct $B$ cell subsets in the peripheral blood of healthy RMs. Flow cytometry was used to phenotypically characterize the $B$ cell compartment in peripheral blood of healthy RMs. (A) Representative dot plots showing gating strategy used to identify B cell subsets: naive (CD21+CD27-), resting memory $\left(\mathrm{CD} 21^{+} \mathrm{CD} 27^{+}\right)$, $\mathrm{mB}_{\text {Act }}\left(\mathrm{CD} 21^{-} \mathrm{CD} 27^{+}\right)$, and tissue memory (CD21 $\left.11^{\mathrm{o} /-} \mathrm{CD} 27^{-}\right)$. (B) MFI of CD20 on B cell subsets. Bars represent mean \pm SEM. (C) Frequencies of $B$ cell subsets in peripheral blood of healthy RMs, with each data point representing an individual animal $(n=45)$. Horizontal lines represent means. (D) Distribution of B cell subsets in healthy human adults $(n=15)$, with each data point representing an individual donor. Horizontal lines represent medians. (E) Activation marker profiles of $B$ cell subsets in healthy RMs $(n=10)$. Shown are representative dot plots (CD20-gated cell subsets overlaid on $T$ cell contour plots) for each $B$ cell subset and corresponding cumulative plots showing percentages of $B$ cell subsets expressing CD40, CD80, CD95, and CD11C. Numbers within plots indicate the frequency of marker-positive cells as a percentage of the respective B cell subset. ${ }^{* \star} P<0.01$; ${ }^{\star * \star} P<0.001$. 

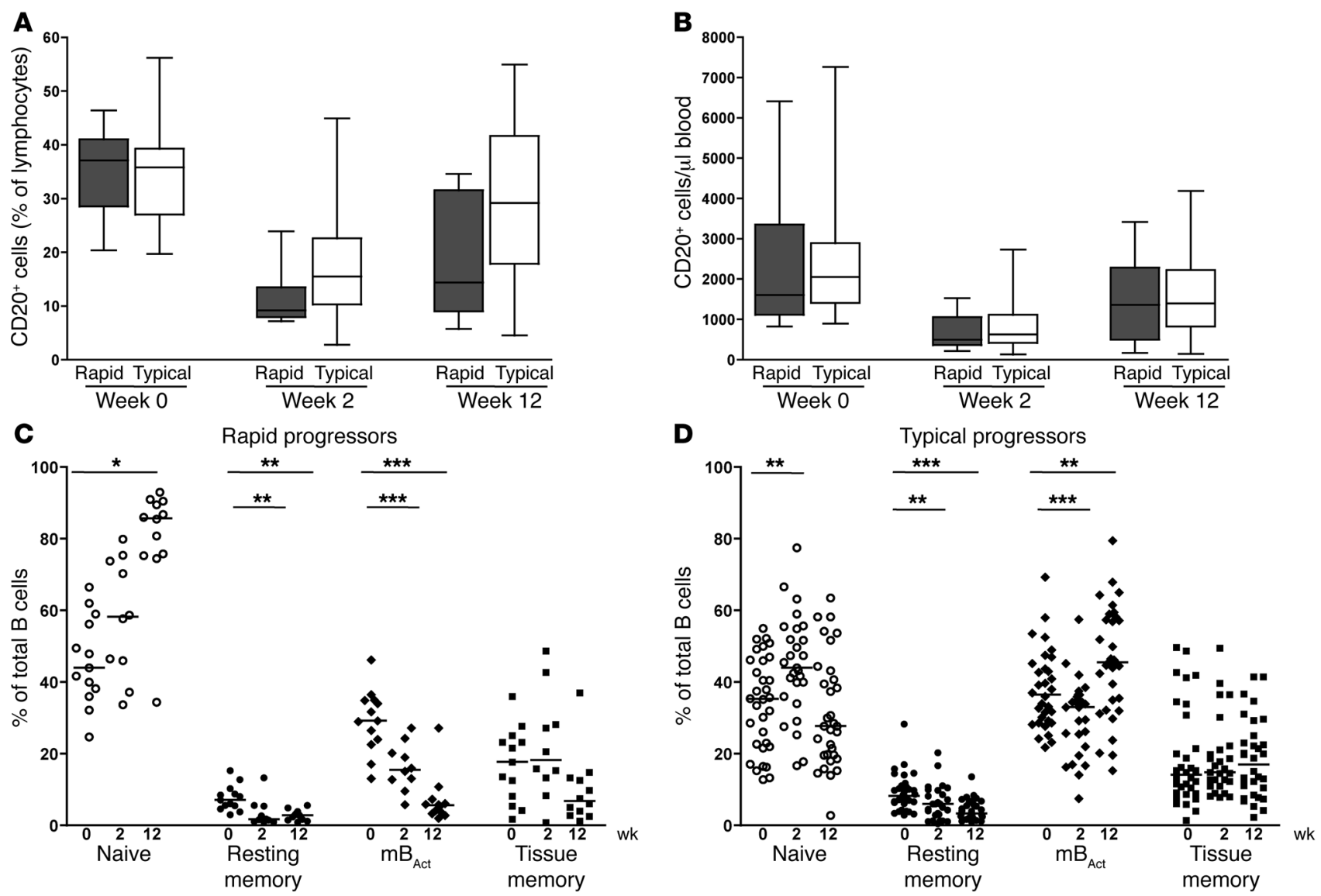

Figure 2

Depletion of $\mathrm{mB}_{\text {Act }}$ cells in rapid progressors following SIV infection in blood. Percentages $(\mathbf{A})$ and absolute counts (B) of total B cells in rapid $(n=13)$ and typical $(n=39)$ progressor RMs before (week 0$)$ and 2 and 12 weeks after SIV infection. Boxes represent 25th-75th percentiles with medians; whiskers represent 5th and 95th percentiles. Percentages of peripheral blood B cell subsets before and after SIV infection in rapid progressors $(n=13)(\mathbf{C})$ and typical progressors $(n=39)(\mathrm{D})$. Each data point represents an individual animal, and horizontal lines represent medians. ${ }^{*} P<0.05 ;{ }^{* *} P<0.01 ;{ }^{* *} P<0.001$.

correlations between both frequency and absolute number of $\mathrm{mB}_{\text {Act }}$ cells by week 2 (Figure 3C and Supplemental Figure 2B), which indicated that the loss of $\mathrm{mB}_{\text {Act }}$ could be an early predictor of rapid disease progression. The correlations were even stronger by week 12 post infection $(r=-0.7, P<0.0001$, for both frequencies and absolute numbers). Furthermore, we observed a significant inverse correlation between the frequency of $\mathrm{mB}_{\text {Act }}$ cells prior to infection and the extent of their depletion at 2 weeks post infection (Figure $3 \mathrm{~B}$ ).

Analyses of total $\mathrm{CD} 4^{+} \mathrm{T}$ cells in the colorectal tissue and total $\mathrm{T}_{\mathrm{CM}}$ cells in blood did not reveal significant differences between the groups at 2 weeks post infection (Figure 3, D and E). By 12 weeks, only the frequency of $\mathrm{T}_{\mathrm{CM}}$ cells in blood was significantly lower $(P=0.02)$ in rapid versus typical progressors. Similarly, the frequency of these cells at 12 weeks, but not at 2 weeks, correlated inversely with set-point viremia (Figures 3, D and E). Thus, the loss of $\mathrm{mB}_{\text {Act }}$ cells is associated with, and may represent an early predictor of, rapid disease progression in RMs.

Early depletion of $m B_{\text {Act }}$ cells is associated with impaired SIV-specific and non-SIV-specific humoral immunity. Both HIV and SIV disease progression are characterized by overwhelming non-HIV/SIV infections that eventually lead to end-stage AIDS and death. We hypothesized that the loss of $\mathrm{mB}_{\text {Act }}$ cells in rapidly progressing animals would have important consequences not only for SIV-specific humoral immune responses, but also for $\mathrm{Ab}$ responses to non-SIV infections. We therefore measured the serum titers of SIV Env-binding Abs in both rapid and typical progressors and found that 5 of 8 rapid progressors had undetectable SIV Env Ab titers through week 20 of infection (Figure 4A). The other 3 rapid progressors mounted a modest anti-Env $\mathrm{Ab}$ response by week 12, and 1 had sustained $\mathrm{Ab}$ titers through week 20. The typical progressors, on the other hand, developed robust anti-Env $\mathrm{Ab}$ responses by 12 weeks post infection, with even higher Ab titers by 20 weeks (Figure 4B).

Intestinal bacterial infections are a significant cause of morbidity in SIV-infected animals, and the causative agents of these infections are usually flagellated, with the flagella representing an important virulence factor (33). We therefore measured serum $\mathrm{Ab}$ titers in response to the common bacterial $\mathrm{Ag}$ flagellin (FliC) as a means to assess the effect of loss of $\mathrm{mB}_{\text {Act }}$ cells on preexisting humoral immunity to common intestinal bacteria that frequently cause clinically relevant infections in immunocompromised hosts (34). Prior to infection, anti-FliC Ab titers were nearly 2 -fold higher in the rapid progressors (median, $1,889 \mathrm{ng} / \mathrm{ml}$ ) than in the typical progressors (median, $982 \mathrm{ng} / \mathrm{ml}$ ), but this difference did not reach statistical significance. By 2 weeks post infection, anti-FliC Ab titers in the 
A

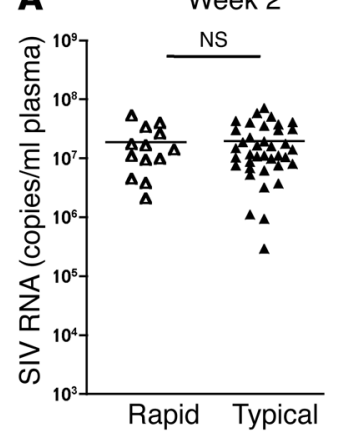

C

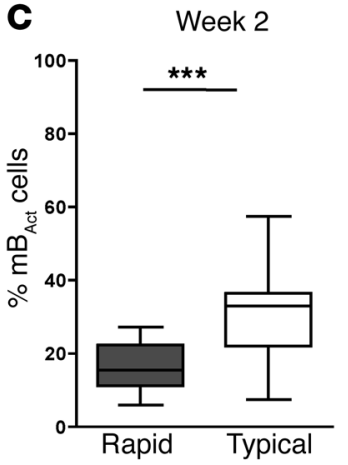

D

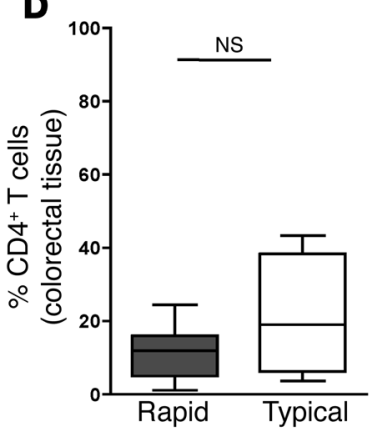

E

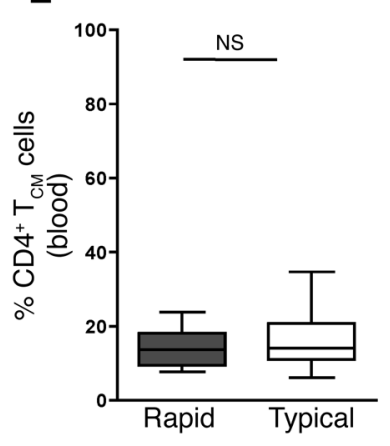

Week 12

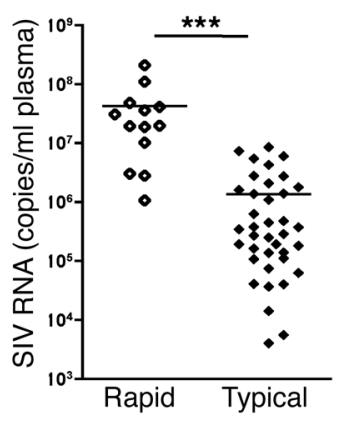

Week 12
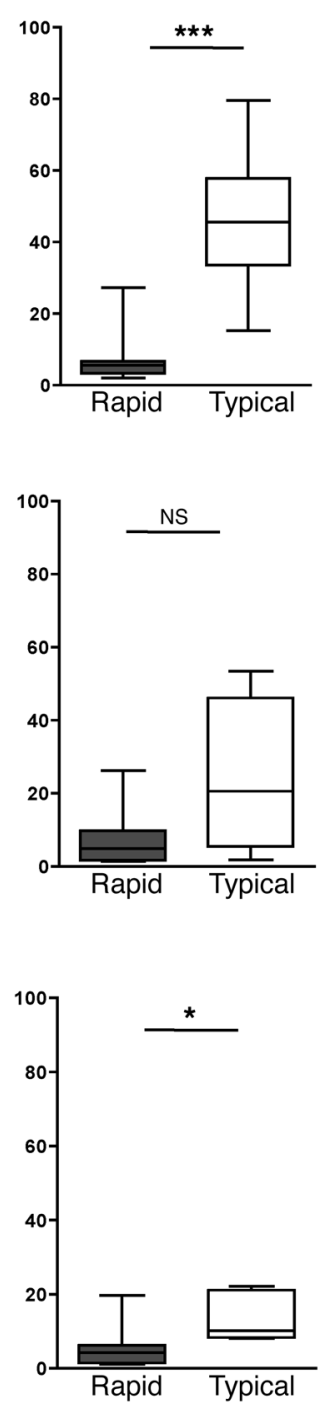

B

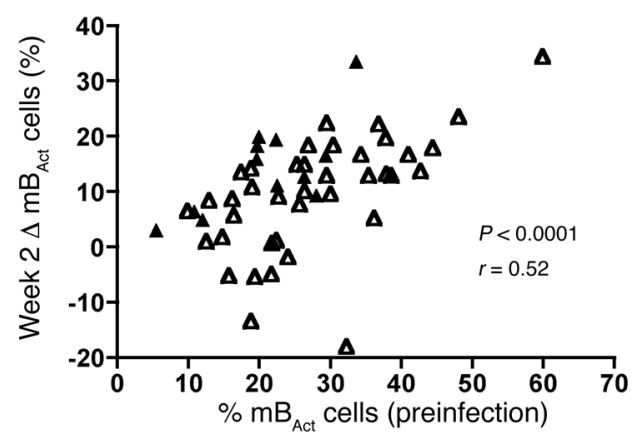

Week 2
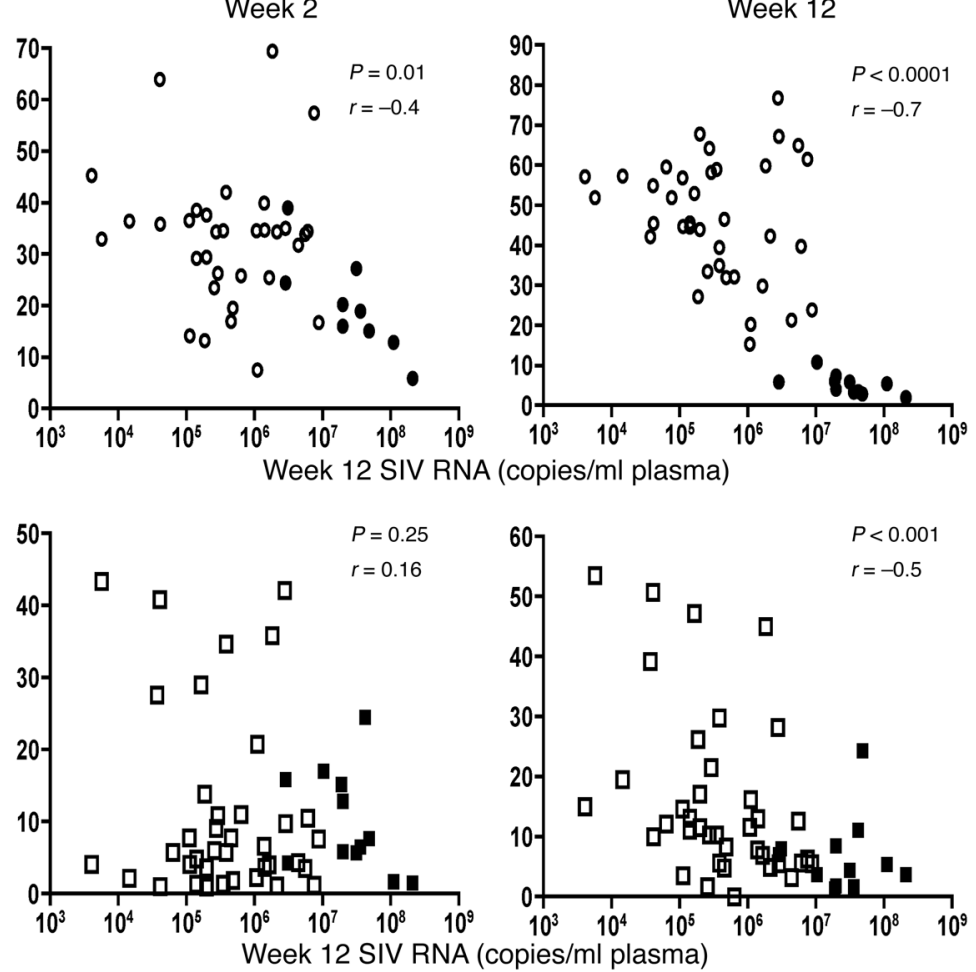

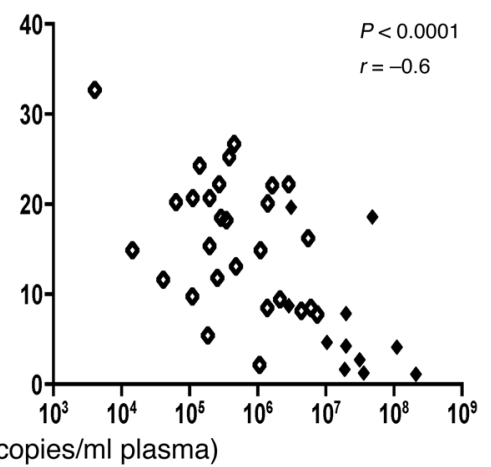

Figure 3

Depletion of $\mathrm{mB}_{\text {Act }}$ cells is an early predictor of disease progression. (A) Plasma SIV viral load in rapid $(n=13)$ and typical $(n=39)$ progressors at 2 and 12 weeks post infection. (B) Correlation between percentages of $\mathrm{mB}_{\text {Act }}$ cells prior to infection and change in $\mathrm{mB}_{\text {Act }}$ cell percentages from week 0 to week 2. (C) Percentages of $\mathrm{mB}_{\text {Act }}$ cells and correlations between set-point viral load and mB $\mathrm{m}_{\text {Act }}$ cells at 2 or 12 weeks post SIV infection. (D) Proportions of total CD4 ${ }^{+} \mathrm{T}$ cells in colorectal tissue, and correlations between set-point viral load and CD4 ${ }^{+} \mathrm{T}$ cells in colorectal tissue at 2 or 12 weeks post SIV infection. (E) Proportion of blood $T_{C M}$ cells and correlations between set-point viral load and blood $T_{C M}$ cells at 2 or 12 weeks after SIV infection. For correlation analyses, filled and open symbols represent rapid and typical progressors, respectively. Boxes represent 25th-75th percentiles with medians, and whiskers represent 5th and 95th percentiles. ${ }^{\star} P<0.05 ;{ }^{* \star} P<0.001$. 
A
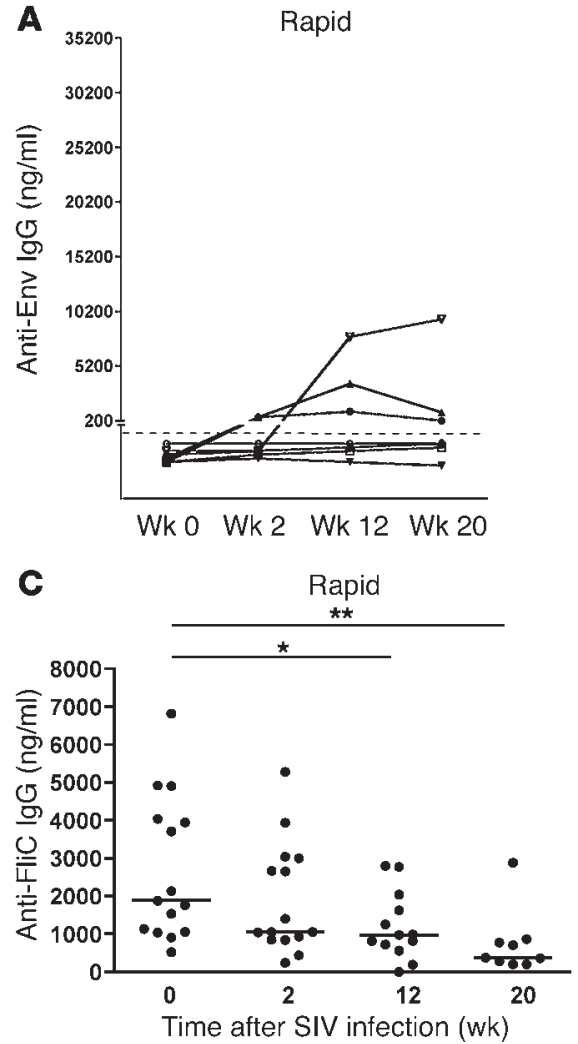

B

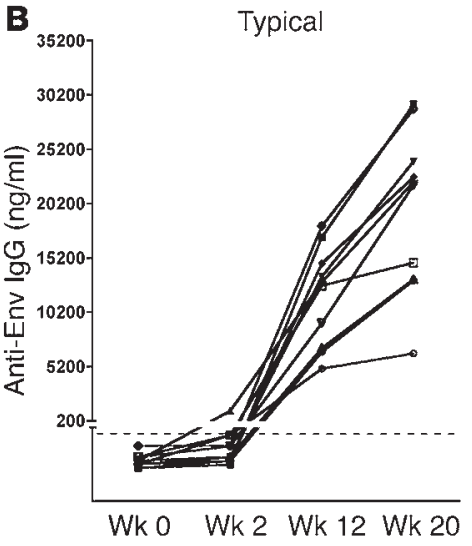

Typical

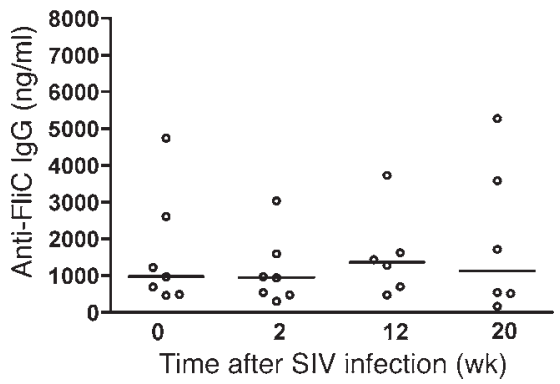

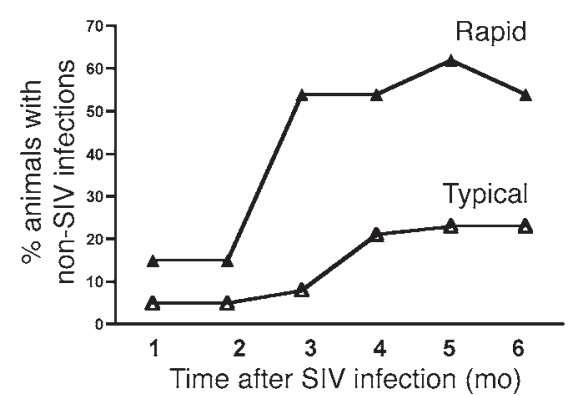

Figure 4

Depletion of $\mathrm{mB}_{\text {Act }}$ cells in rapidly progressing SIV infection impairs SIV-specific and non-SIV-specific humoral immune responses. Serum titers of anti-SIV Env IgG Ab in (A) rapid progressors $(n=8)$ and $(\mathbf{B})$ typical progressors $(n=10)$ before and at weeks 2,12 , and 20 post SIV infection. Dashed lines denote the $200-\mathrm{ng} / \mathrm{ml}$ assay limit of detection. (C) Serum titers of anti-FliC IgG Ab in rapid $(n=15)$ and typical $(n=7)$ progressors before and at weeks 2,12 , and 20 post SIV infection. Each data point represents an individual animal, and horizontal lines represent medians. (D) Incidence of non-SIV infections in rapid $(n=15)$ and typical $(n=39)$ progressors following SIV infection. See Supplemental Tables 1 and 2 for additional information. ${ }^{*} P<0.05 ;{ }^{*} P<0.01$

rapid progressors were significantly lower, and further decreased as the infection progressed through week 20 ( $P<0.01$; Figure $4 \mathrm{C})$. In contrast, anti-FliC $\mathrm{Ab}$ titers did not change significantly in typical progressors $(P=0.9$; Figure $4 \mathrm{C})$. We also analyzed the incidence of non-SIV infections in both groups over a 6 -month period following initial SIV infection and found that a wide variety of other infections occurred in the animals (Supplemental Tables 1 and 2). These included bacterial (Campylobacter, Shigella, enteropathogenic E. coli), parasitic (Trichomonas, whip worms, Giardia), and yeast (Candida) infections. Importantly, rapid progressors succumbed to these infections as early as 1 month post infection, and by 3 months post infection, greater than $50 \%$ of them had developed infections compared with less than $10 \%$ of the typical progressors. This rate of infection in rapid progressors was sustained throughout the 6-month period (Figure 4D and Supplemental Tables 1 and 2).

Preferential depletion of $\mathrm{PD}-1^{+} m B_{\text {Act }}$ cells following SIV infection of $R M s$. The coinhibitory receptor PD-1 has been shown to play an important role in $\mathrm{T}$ cell exhaustion and survival during chronic HIV (15-17) and SIV infections $(18,19,35)$. To understand the role of PD-1 in B cell dysfunction and survival, we analyzed PD-1 expression on different $\mathrm{B}$ cell subsets before and after infection. Prior to infection, a substantial proportion of all 3 memory B cell subsets, but not naive B cells, expressed PD-1 (Figure 5, A and B). Moreover, the $\mathrm{mB}_{\text {Act }}$ cells not only had the highest proportion of PD- $1^{+}$cells, but also expressed the highest amounts of PD-1 (based on MFI, data not shown) compared with the other subsets. Given the high expression of PD- 1 on the $\mathrm{mB}_{\text {Act }}$ cells, we analyzed the distribution of $\mathrm{PD}-1^{+} \mathrm{mB}_{\text {Act }}$ cells in rapid and typical progressors as a percentage of total B cells (Figure 5C). Interestingly, the depletion of $\mathrm{mB}_{\text {Act }}$ cells in rapid progressors translated into preferential depletion of PD- $1^{+} \mathrm{mB}_{\text {Act }}$ cells by week 2 , which was sustained through week 12 post infection (Figure 5C). In contrast, the proportions of $\mathrm{PD}-1^{+}$memory $\mathrm{B}$ cells in typical progressors decreased significantly by week 2 , but were restored to preinfection levels by week 12 (Figure $5 \mathrm{C}$ ). This raised the possibility that $\mathrm{PD}-1$ may play a role in depletion of $\mathrm{mB}_{\text {Act }}$ cells.

$P D-1$ regulates survival of $m B_{A c t}$ cells in $R M$ s. To investigate a possible role for PD-1 signaling in depletion of $\mathrm{mB}_{\text {Act }}$ cells, we used the human hepatoma cell line Huh-7.5 transfected with PD-L1 (Huh-7.5-PD-L1) as a source of ligand for PD-1-expressing $\mathrm{mB}_{\text {Act }} \mathrm{B}$ cells (Supplemental Figure 3A). Coculture of purified B cells from SIV-infected RMs with Huh-7.5-PD-L1 significantly increased $\mathrm{mB}_{\text {Act }}$ cell apoptosis $(P<0.0001$; Figure 6, A and B). Apoptosis of naive B cells was not significantly altered in the presence of PD-L1, consistent with their lower PD-1 expression (Figure 6C). Moreover, stimulation with PD-L1 did not enhance apoptosis of $\mathrm{mB}_{\text {Act }}$ cells from uninfected RMs (Supplemental Figure 3B). Thus, PD-1 signaling during SIV infection plays an important role in regulating survival of $\mathrm{mB}_{\text {Act }}$ cells. 
A

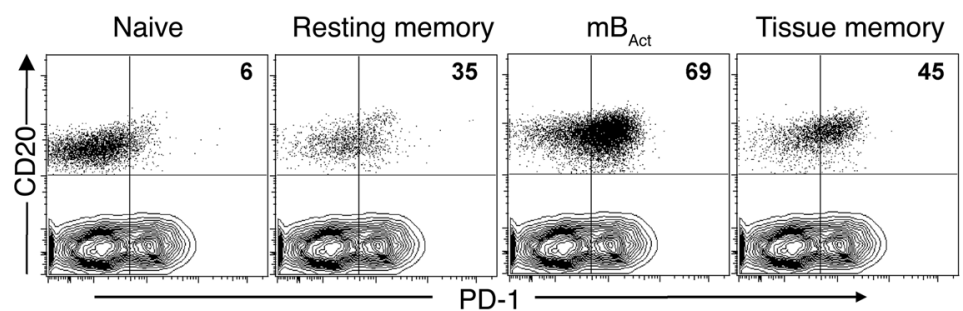

C

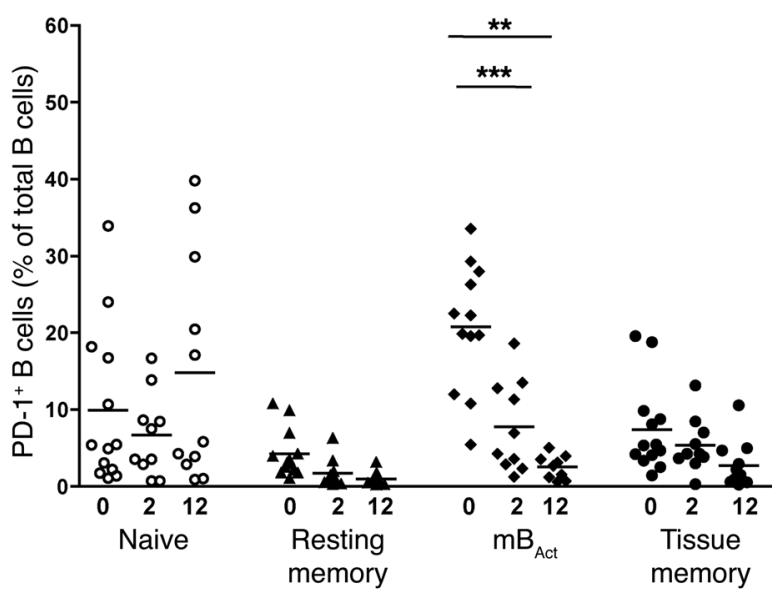

B

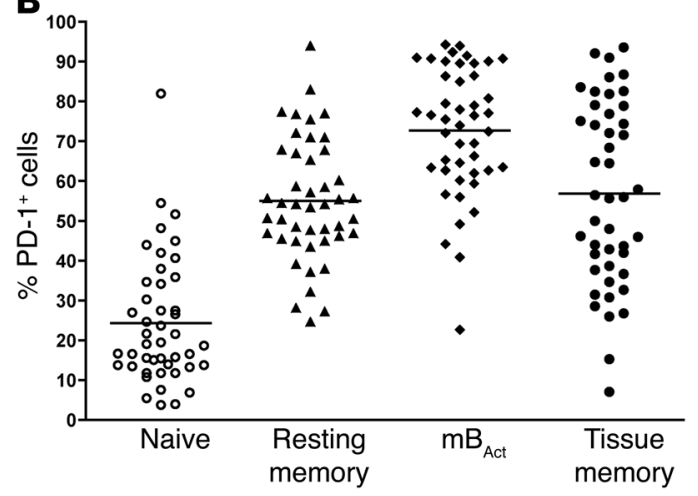

Typical

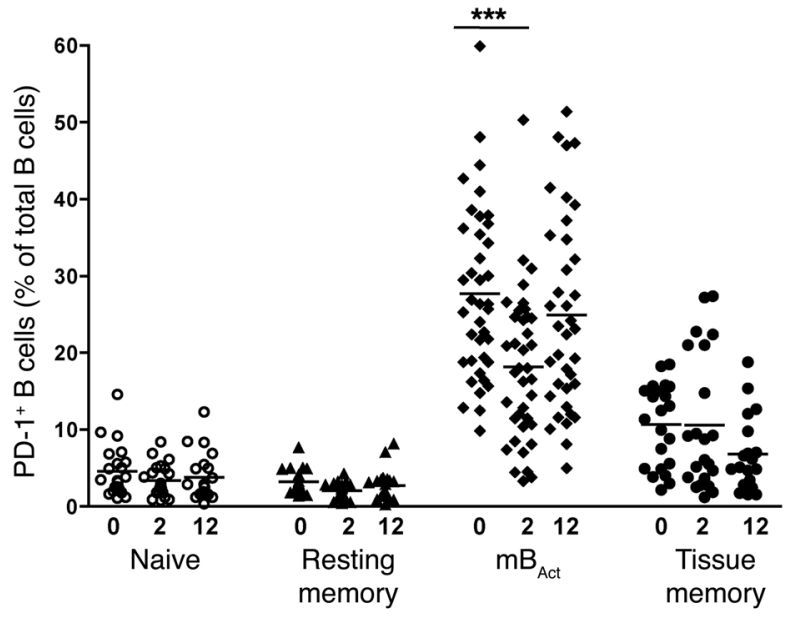

Figure 5

Preferential depletion of PD-1+ $\mathrm{mB}_{\text {Act }}$ cells in rapid progressors following SIV infection. (A) Representative FACS plots showing PD-1 expression on B cell subsets of a healthy RM. Dot plots of CD20-gated cell subsets overlaid on T cell contour plots. Numbers represent proportion of PD-1+ cells, expressed as a percentage of the respective B cell subset. (B) Proportions of PD-1+ B cell subsets in healthy RMs $(n=45)$. (C) Proportions of PD-1+ B cell subsets (expressed as a percentage of total B cells) in rapid $(n=13)$ and typical $(n=39)$ progressors before and at 2 and 12 weeks post SIV infection. ${ }^{* *} P<0.01 ;{ }^{* *} P<0.001$.

Memory B cells in HIV-infected humans are primed to undergo both spontaneous and death receptor-induced apoptosis, notably through the Fas-FasL pathway $(10,27,36)$, but there is little information on what role the Fas-FasL pathway plays in B cell apoptosis during SIV infection. A recent study showed an association between Fas-induced apoptosis and high PD-1 expression on $\mathrm{CD}^{+} \mathrm{T}$ cells in HIV-infected individuals (37), and we wondered whether this holds true for the high $\mathrm{PD}-1$-expressing $\mathrm{mB}_{\text {Act }}$ cells. In order to determine susceptibility of $\mathrm{mB}_{\text {Act }}$ cells to Fas-mediated apoptosis and to identify a possible role for PD- 1 in $\mathrm{mB}_{\text {Act }}$ cell depletion, we cultured PBMCs from 9 SIV-infected animals with and without recombinant human FasL (rFasL) in combination with PD-1 blockade and analyzed annexin $\mathrm{V}$ expression on $\mathrm{mB}_{\text {Act }}$ cells after 24 hours of culture (Supplemental Figure 3C). In all 9 animals, we saw a significant increase in apoptosis with the addition of rFasL to the cultures; interestingly, in 7 animals, we observed a decrease in FasL-mediated apoptosis following PD-1 blockade (Supplemental Figure 3C).

We next investigated whether the presence of PD-1 on memory $B$ cells affects their ability to proliferate and differentiate into Ab-secreting cells (ASCs; Figure 6D and Supplemental Figure 3D).
We set up an in vitro ELISpot assay to track total IgM-, IgG-, and SIV gp130 IgG-producing memory B cells, based on a previously described method (38). Following polyclonal stimulation and in the presence of anti-PD-1 blocking $\mathrm{Ab}$, there was a significant increase in total IgM, IgG, and SIV gp130-specific IgG ASCs. This increased ASC generation could be the result of enhanced proliferative capacity or survival of memory $B$ cells in the presence of anti-PD-1 blocking Ab. These results were consistent with our previous report demonstrating that in vivo blockade of PD-1 in RMs with chronic SIV infection results in increased titers of SIV Env-binding Ab (19).

In vivo PD-1 blockade enhances both non-SIV-specific and SIV-specific bumoral immunity. To further investigate the restorative potential of PD-1 blockade on the B cell compartment, we assessed the effect of in vivo PD-1 blockade on non-SIV-specific and SIV-specific Ab responses (Figure 7). We measured the titers of anti-FliC and antiSIV Gag p27 antibodies in SIV-infected RMs that received 4 doses of either anti-PD-1 Ab or control $\mathrm{Ab}$ at 10 weeks post infection (19). The titers of anti-FliC Ab increased 2-fold in 3 of 5 anti-PD-1 $\mathrm{Ab}$-treated animals by day 21 following blockade (Figure 7A). No significant increase was observed in either of the control Ab- 

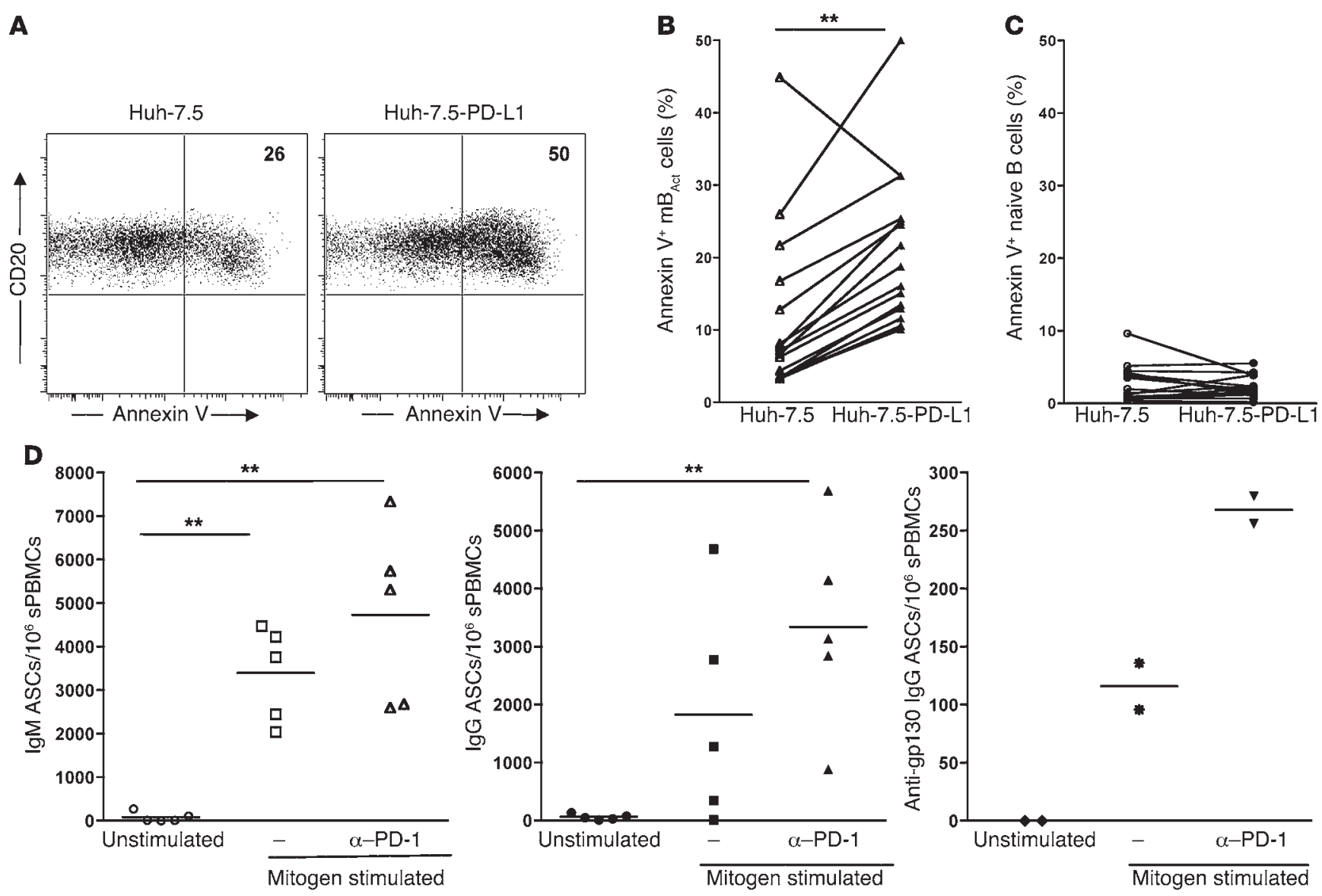

Figure 6

PD-1 regulates survival of $\mathrm{mB}_{\mathrm{Act}}$ cells in SIV-infected RMs. (A) Representative dot plots showing percentages of annexin $\mathrm{V}^{+} \mathrm{mB}_{\mathrm{Act}}$ cells following culture with Huh-7.5 or Huh-7.5-PD-L1 cells. Summary of annexin V binding on (B) $\mathrm{mB}_{\text {Act }}$ cells and (C) naive B cells following culture with Huh-7.5 or Huh-7.5-PD-L1 cells. Symbols represent individual SIV+ animals $(n=16)$; data obtained from 4 independent experiments. (D) In vitro blockade of PD-1 enhanced total IgM-, IgG-, and SIV-specific ASCs following polyclonal stimulation of PBMCs from SIV-infected RMs. Each data point represents an individual animal, and horizontal lines represent medians. ${ }^{\star \star} P<0.01$.

treated animals. Similarly, we observed an increase in the titers of anti-SIV p27 Ab in 4 of 5 anti-PD-1 Ab-treated animals following blockade (Figure 7B). This increase in SIV Gag-specific Ab titers was consistent with increased titers of SIV Env-binding Ab in anti-PD-1 mAb-treated RMs (19). These results demonstrate that in vivo PD-1 blockade during early chronic SIV infection enhances humoral immunity against non-SIV as well as SIV Ags, presumably as a result of enhanced survival of memory B cells. We measured the frequency of total $\mathrm{mB}_{\text {Act }}$ cells in blood following in vivo blockade and did not observe a significant increase (data not shown). However, it may be important to measure the frequency of these cells in multiple tissues to rule out the possibility of differential trafficking following blockade.

$m B_{\text {Act }}$ cells are maintained in SIV-infected SMs. To further understand the association between depletion of $\mathrm{mB}_{\text {Act }}$ cells and progressive SIV infection, we studied a cohort of uninfected and SIVinfected SMs, which - like other natural hosts of SIV - rarely progress to AIDS (Figure 8). Healthy SMs had far fewer circulating total B cells (about $12 \%-15 \%$ of lymphocytes) than did healthy RMs (30\%-40\% of lymphocytes; see Figure 2 A). Unlike in RMs, we did not observe lower frequencies of circulating total B cells in $\mathrm{SIV}^{+} \mathrm{SMs}$ (Figure 8A). In SMs, we also identified 4 B cell sub- sets based on CD21 and CD27 expression, although the relative distribution of these subsets was different from that in RMs (Figure 8B). Naive B cells constituted the major peripheral blood $B$ cell subset ( $>40 \%$ ), and the majority memory B cell subset was the tissue memory B cells, not $\mathrm{mB}_{\text {Act }}$ cells as in RMs. Like RMs, less than $10 \%$ of circulating memory B cells in the SMs were resting memory B cells; however, the percentage of $\mathrm{SM} \mathrm{mB}_{\text {Act }}$ cells was significantly lower compared with RMs. In addition, the distribution of all $4 \mathrm{~B}$ cell subsets was comparable in $\mathrm{SIV}^{+}$and $\mathrm{SIV}^{-} \mathrm{SMs}$ (Figure 7B), which suggests that memory B cells are not depleted in chronically infected $\mathrm{SIV}^{+} \mathrm{SMs}$.

We also analyzed the expression of PD-1 on different B cell subsets in $\mathrm{SIV}^{+}$and SIV- SMs. Although PD-1 expression was high on both $\mathrm{SM}$ and $\mathrm{RM} \mathrm{mB}_{\text {Act }}$ cells, on $\mathrm{SM}$ tissue memory $\mathrm{B}$ cells, unlike the RMs, PD-1 expression was equally high. In $\mathrm{SIV}^{+} \mathrm{SMs}$, the proportion of all $4 \mathrm{~B}$ cell subsets expressing PD-1 was similar to that in SIV- SMs (Figure 8C), which indicates that SIV infection did not significantly alter the proportion of PD-1-expressing $\mathrm{mB}_{\text {Act }}$ cells. These results suggest that in $\mathrm{SIV}^{+} \mathrm{SMs}$, the B cell compartment, particularly the $\mathrm{mB}_{\text {Act }}$ cell subset, is not severely perturbed. Maintenance of an intact B cell compartment may be another mechanism through which SMs avoid disease progression. 

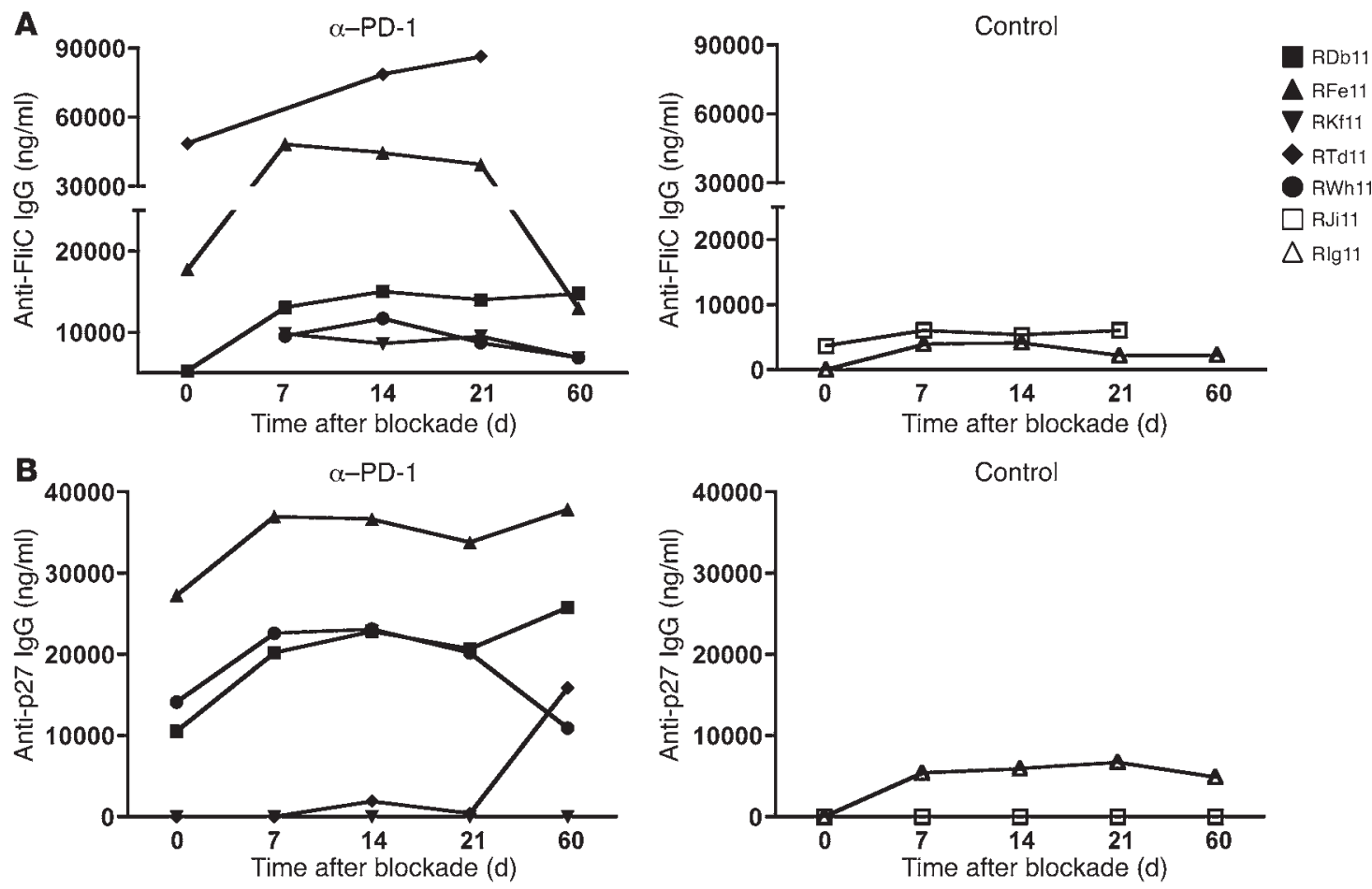

Figure 7

In vivo PD-1 blockade enhances both non-SIV-specific and SIV-specific humoral immunity. PD-1 blockade was performed in 5 SIV-infected animals at 10 weeks following infection. 2 SIV-infected animals treated with an isotype Ab served as controls. (A) Serum anti-FliC IgG Ab titers. (B) Serum anti-Gag p27 IgG Ab titers.

\section{Discussion}

Generalized B cell dysfunction is an important feature of HIV and pathological SIV infections. An association between loss of total memory B cells and loss of CD4 ${ }^{+} \mathrm{T}$ cells was previously shown in HIV-infected individuals (12), which suggested that total memory $\mathrm{B}$ cell loss may be a useful marker of disease progression. While comparable B cell dysfunctions have been identified in SIV-infected RMs $(8,9,14,28)$, the kinetics, specific B cell subsets affected, mechanisms involved, and role of B cell defects in rapid disease progression are not well defined. Here, we demonstrated that $\mathrm{mB}_{\text {Act }}$ cells are rapidly depleted following pathogenic SIV infection and that this depletion strongly influences disease progression. Importantly, loss of $\mathrm{mB}_{\text {Act }}$ cells in rapid progressors was associated with a significantly higher rate of acquisition of various non-SIV infections. We also showed that the PD-1 pathway plays an important role in the depletion/survival of these $\mathrm{mB}_{\text {Act }}$ cells. Our results highlight the rapid and profound loss of $\mathrm{mB}_{\text {Act }}$ cells as an important mechanism of rapid disease progression and consequent impaired humoral immune response against SIV and non-SIV infections.

A key finding of our study was the strong association between loss of total $\mathrm{mB}_{\text {Act }}$ cells and higher set-point viremia (and thus rapid disease progression). Given that strong SIV-specific Ab responses are not detectable until several weeks post infection (9), presumably, the $\mathrm{mB}_{\text {Act }}$ cells being depleted during the first few weeks would be primarily non-SIV-specific and constitute an integral part of preexisting humoral immunity to non-SIV infections. The mechanisms by which these non-SIV-specific $\mathrm{mB}_{\text {Act }}$ cells influence set-point viremia and disease progression are not completely clear. Our results suggest that the early drastic loss of
$\mathrm{mB}_{\text {Act }}$ cells in rapid disease progressors contributes to a substantially higher rate of acquisition of other infections, which in turn contributes to immune hyperactivation and thus higher set-point viremia and rapid disease progression.

Another interesting finding of our study is the significantly larger proportion of $\mathrm{mB}_{\text {Act }}\left(\mathrm{CD} 20^{\text {hi }} \mathrm{CD} 21^{-} \mathrm{CD} 27^{+}\right)$cells found in RMs compared with humans. The fact that the majority of circulating B cells in RMs are CD21- suggests that RMs have a higher degree of basal immune activation compared with humans. The reasons for such a discrepancy between base levels of activation in RMs and humans remains to be elucidated, but may be related to both host and environmental factors, including housing conditions and intrinsic behavior of the animals. Confounding this theory, however, is the fact that SMs do not have similar high levels of basal activation, despite housing conditions and behavior comparable to those of RMs.

We also describe here, for the first time to our knowledge in RMs, a memory B cell subset that lacked both CD27 and CD21 expression. We likened this subset to the recently described tissue-like memory B cell subset in HIV-infected viremic individuals (22). Comparable human unconventional/tissue-like memory B cells have gained recent attention because of their expansion and accumulation in viremic HIV-infected individuals as well as their association to other disease states, including malaria and common variable immune deficiency $(22,39,40)$. This is an intriguing subset that may have important consequences for disease pathogenesis and merits further study. Our ability to identify such a subset in nonhuman primates presents a unique opportunity to better understand their biology and function. 

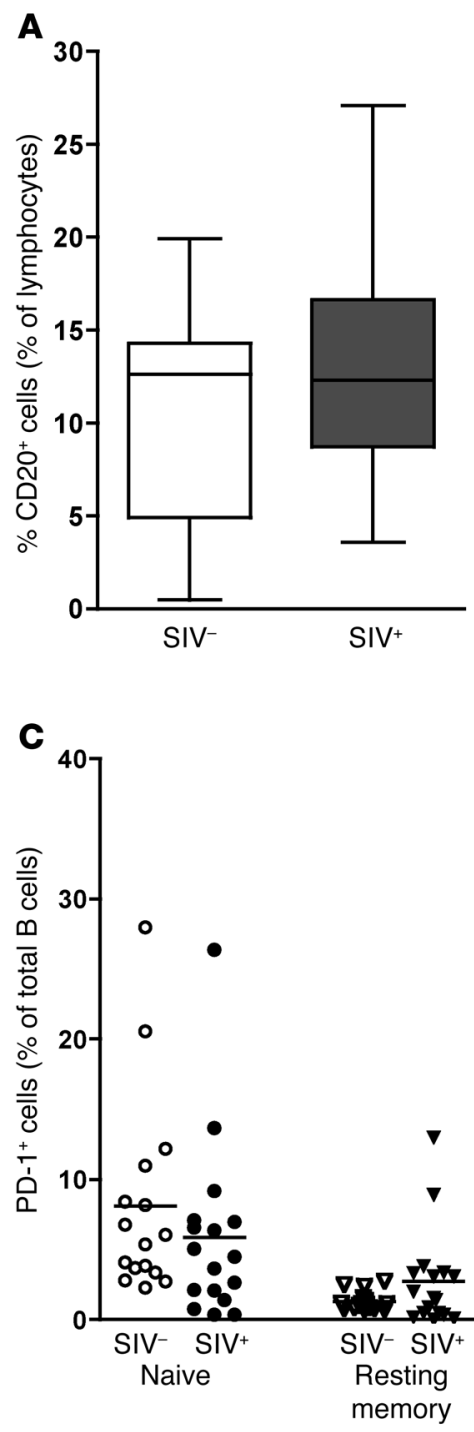

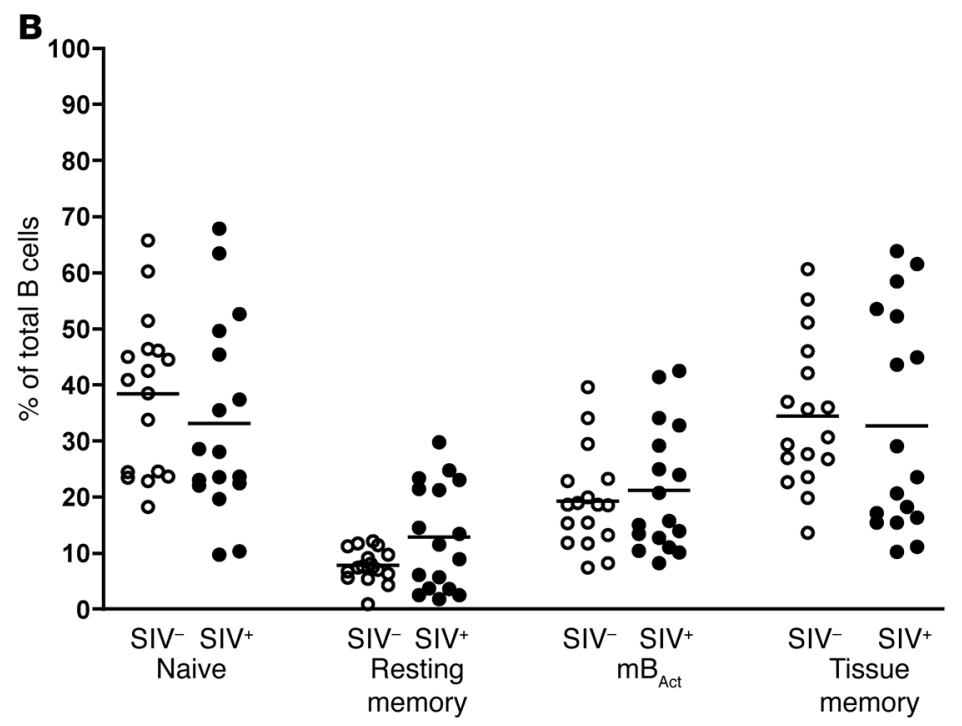
memory

\section{Figure 8}

$\mathrm{mB}_{\text {Act }}$ cells are not depleted in SIV-infected SMs. (A) Percentage of total B cells in SIV- $(n=9)$ and SIV ${ }^{+}(n=13) \mathrm{SMs}$. Boxes represent 25th-75th percentiles with medians, and whiskers represent 5th and 95th percentiles. (B) Percentage of B cell subsets (expressed as a

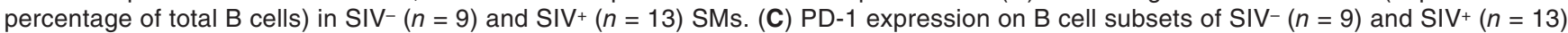
SMs. The proportions of PD-1+ cells are expressed as a percentage of total CD20+ cells. Each data point represents an individual animal, and horizontal lines represent medians.

Depletion of $\mathrm{mB}_{\text {Act }}$ cells from the blood likely occurs via a combination of mechanisms, including migration to other sites/tissues, decreased survival, and/or increased apoptosis. A recent study suggested that the decrease in circulating memory B cells following SIV infection mainly resulted from trafficking to lymphoid organs, with a rebound occurring once the cells returned back to the circulation from the tissues (14). This may be the case in the typical progressors, in which we observed a rebound in memory B cells by week 12, but not in rapid progressors, in which memory B cell loss was sustained. Moreover, our results strongly suggest decreased survival/increased apoptosis as a mechanism of depletion of $\mathrm{mB}_{\text {Act }}$ cells and furthermore invoke a role for PD-1.

Our results support a role for PD-1 in the deletion/survival of $\mathrm{mB}_{\text {Act }}$ cells in SIV infection. We found that in vitro stimulation of $\mathrm{mB}_{\text {Act }}$ cells with PD-L1 induced their deletion through apoptosis, and blockade of the PD-1 pathway in vitro increased their survival and proliferation. In addition, in vivo blockade of PD-1 led to increased titers of Ab to SIV Ags and bacterial FliC. Interestingly, Fas-mediated apoptosis of $\mathrm{mB}_{\text {Act }}$ cells was also decreased following blockade of PD-1, which suggests that both Fas-mediated and PD-1-mediated pathways of apoptosis may be connected in some way. This presents the interesting possibility that Fas-mediated apoptosis could be modulated through PD-1 blockade. Given the attenuated disease course observed in SIV-infected animals treated with a FasL-blocking Ab (41), PD-1 blockade may thus be a means to enhance humoral immune responses through modulation of both the PD-1 and Fas pathways. Given the uniformly high expression of PD- 1 on the majority of $\mathrm{mB}_{\text {Act }}$ cells, the possibility of PD-1 ligand expression being a determining factor in their deletion through the PD-1 pathway cannot be excluded. While we did not 
specifically study PD-1 ligands in this report, a few studies show upregulation of PD-L1 (B7-H1) in progressive HIV infection $(42,43)$. It would be interesting to investigate PD-1 ligand expression in rapid and typical progressor RMs.

Of all the $\mathrm{B}$ cells subsets we studied here, $\mathrm{mB}_{\text {Act }}$ cells expressed the highest amount of PD-1. PD- 1 expression on $\mathrm{CD}^{+} \mathrm{T}$ cells may be related to their differentiation stage and activation status, and the majority of Ag-experienced committed $\mathrm{CD}^{+}$cells, which may require tighter regulation, have the highest PD-1 expression (44). Similarly, $\mathrm{mB}_{\text {Act }}$ cells, which likely have the lowest threshold of activation, probably require the tightest regulation, hence the high PD-1 expression on this subset. This would be an important mechanism for preventing hyperactivation and autoimmunity. Indeed, studies on the effects of PD-1 signaling in B cells indicate that PD-1 may downmodulate excessive and prolonged activation by elevating the threshold for restimulation (45). Another way to interpret our results is that pathogenic SIV infection results in accumulation of $\mathrm{PD}-1^{-} \mathrm{mB}_{\text {Act }}$ cells, which may contribute to hypergammaglobulinemia and autoimmunity. As has been demonstrated in studies of $P D-1^{-/-}$mice (20), this may be an important mechanism underlying the development of autoimmune phenomena in SIV.

Our finding that SIV-infected SMs did not lose $\mathrm{mB}_{\text {Act }}$ cells further supports a role for maintenance of these cells in preventing rapid disease progression, since SIV-infected SMs rarely develop AIDS. Given that higher levels of $\mathrm{mB}_{\text {Act }}$ prior to infection directly correlate with higher depletion of these cells following SIV infection in RMs, the levels of $\mathrm{mB}_{\text {Act }}$ cells prior to infection may influence rapid disease progression. We postulate that individuals with relatively high levels of $\mathrm{mB}_{\text {Act }}$ cells prior to HIV infection may be at higher risk for faster disease progression. Multiple factors, including the incidence of non-HIV infections, could influence the frequency of $\mathrm{mB}_{\text {Act }}$ cells in humans. Indeed, previous studies in humans reported a faster rate of HIV-1 disease progression in developing compared with developed countries $(46,47)$. Furthermore, concurrent infections with other pathogens of bacterial, helminthic, or protozoan origin have been shown to markedly affect the severity and course of disease progression (48). It would be interesting to determine whether individuals living in resource-poor nations, where the incidence of HIV infections is highest, indeed have a higher proportion of $\mathrm{mB}_{\text {Act }}$ cells prior to infection, and how this may relate to disease progression. Identification of an early predictor for rapid HIV progression will greatly enhance our ability to treat and control the HIV/AIDS epidemic worldwide.

\section{Methods}

Study subjects. 52 young adult male RMs (median age, 2.8 years; range, 2.3-4.1 years) and $34 \mathrm{SMs}, 17 \mathrm{SIV}^{-}$and $17 \mathrm{SIV}^{+}(12$ male, 7 female; median age, 14 years; range, 9-25 years) from the Yerkes breeding colony were cared for under guidelines established by the Animal Welfare Act and the NIH Guide for the Care and Use of Laboratory Animals, using protocols approved by the Emory University Institutional Animal Care and Use Committee. The rapid and typical progressor RMs had similar

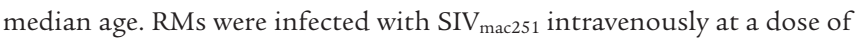
$100 \mathrm{TCID}_{50}$ and were followed longitudinally. N. Miller (NIH, Bethesda, Maryland, USA) provided the challenge stock. SMs were housed in colonies of 50-60 animals, and SIVsm is endemic in this population; all but $1 \mathrm{SM}$ used in the study acquired infection naturally. $15 \mathrm{HIV}^{-}$blood donors were recruited after informed consent, in accordance with the Institutional Review Board of Emory University.
Phenotypic analysis by flow cytometry. Surface lymphocyte stainings were performed using $100 \mu \mathrm{l}$ whole blood samples using multiparameter, multicolor analysis as previously described (19). Lymphocytes were obtained from necropsy tissue as previously described (19). We used mouse antihuman Abs against CD3 (clone SP34-2; BD Biosciences), CD4 (clone L-200; BD Biosciences), CD28 (clone CD28.2; BD Biosciences), CD21 (clone B-Ly4; BD Biosciences), CD27 (clone M-T2712; BD Biosciences), CD80 (clone L307.4; BD Biosciences), CD11c (clone S-HCL-3; BD Biosciences), CD20 (clone 2H7; eBiosciences), CD40 (clone MAB89; Beckman Coulter), CD95 (clone DX2; Caltag), and PD-1 (clone EH12; ref. 19). Cells were analyzed on a LSRII flow cytometer (BD Immunocytometry Systems), and data were analyzed with Flowjo software version 8.8.2 (Treestar).

Apoptosis assays. Huh-7.5.A2.PD-L1 cells (referred to herein as Huh-7.5PD-L1) were used to assess PD-L1-mediated apoptosis of $\mathrm{mB}_{\text {Act }}$ cells, with Huh-7.5 cells as control. Huh-7.5-PD-L1 cells expressed human PD-L1 stably under CMV promoter and Neomycin resistance. Both cell lines were seeded onto separate 24 -well plates at $5 \times 10^{5}$ cells/well and incubated at $37^{\circ} \mathrm{C}$ for $12-16$ hours. Purified B cells (>95\% purity, isolated from PBMCs using NHP-specific CD20 microbeads; Miltenyi Biotec) were then added and incubated for 24 hours at $37^{\circ} \mathrm{C}$, after which the cells were stained for CD20, CD27, CD21, and annexin V and immediately analyzed on an LSRII flow cytometer.

To determine rates of spontaneous and FasL-mediated apoptosis, PBMCs from $9 \mathrm{SIV}^{+}$animals were plated in 96 -well round-bottomed tissue culture plates at $2.5 \times 10^{5}$ cells/well in the presence or absence of $10 \mathrm{ng} / \mathrm{ml} \mathrm{rFasL}$ (R\&D Systems) with or without $10 \mu \mathrm{g} / \mathrm{ml}$ anti-human PD-1 Ab (clone EH12 with mouse variable and human IgG1; ref. 19). Plates were incubated for 24 hours at $37^{\circ} \mathrm{C}$, after which the cells were stained for CD20, CD27, CD21, and annexin $\mathrm{V}$ and analyzed immediately on an LSRII flow cytometer.

ELISA. The titers of anti-Env IgG (49), anti-Gag p27 IgG (50), and antiFliC IgG (51) were determined as previously described. For anti-Env Ab, cell culture supernatants of transient transfections of $293 \mathrm{~T}$ cells with DNA/SIV239 VLP served as the source of Ag (Env). ELISA plates (Costar, Corning Life Sciences) were coated with ConA (Vector Laboratories) by incubating $100 \mu \mathrm{l}$ of $25 \mu \mathrm{g} / \mathrm{ml}$ Con A in $10 \mathrm{mM}$ HEPES buffer ( $\mathrm{pH} 7.5$ ) with $0.15 \mathrm{M} \mathrm{NaCl}, 1 \mathrm{mM} \mathrm{CaCl}_{2}$, and $1 \mathrm{mM} \mathrm{MnCl}_{2}$ overnight at $4^{\circ} \mathrm{C}$. Plates were washed 6 times with PBS containing 0.05\% Tween-20 (PBS-tween), after which $100 \mu \mathrm{l}$ of undiluted VLP supernatant was added, and incubated for 1 hour at room temperature. For anti-FliC Ab titers, ELISA plates were coated with native FliC derived from S. typhimurium at $100 \mathrm{ng} /$ well in bicarbonate buffer ( $\mathrm{pH} 9.6$ ), and plates were incubated overnight at $4{ }^{\circ} \mathrm{C}$. For anti-p27 Ab titers, ELISA plates were coated with recombinant gag p27 $\mathrm{SIV}_{\text {mac251 }}$ (Immunodiagnostics Inc.) at $100 \mathrm{ng} /$ well in PBS, and plates were incubated overnight at $4{ }^{\circ} \mathrm{C}$. For all assays, plates were then washed 6 times with PBS-tween, then blocked for 1 hour at room temperature with $100 \mu \mathrm{l}$ blocking buffer (PBS-tween with $4 \%$ whey and 5\% dry milk). Test sera were diluted in PBS-tween with 4\% whey and $100 \mu \mathrm{l}$ of serial 3-fold dilutions added to duplicate wells and incubated for 1 hour at room temperature. The plates were then washed 6 times with PBS-tween, and bound Ab was detected using peroxidase-conjugated anti-monkey IgG (Accurate Chemi$\mathrm{cal}$ and Scientific Corp.) and TMB substrate (KPL). Reactions were stopped with $100 \mu \mathrm{l}$ of $2 \mathrm{~N} \mathrm{H}_{2} \mathrm{SO}_{4}$. A standard curve generated using affinity-purified goat anti-monkey IgG (capture $\mathrm{Ab}, 10 \mu \mathrm{g} / \mathrm{ml}$ ) and known amount of rhesus IgG (both from Accurate Chemicals) was included on all plates. Standard curves were fitted and sample concentrations interpolated as ng $\mathrm{Ab} / \mathrm{ml}$ serum using SOFTmax 2.3 software (Molecular Devices). The concentrations of IgG are relative to the standard curve.

Memory B cell ELISpot assay. Memory B cell ELISpot assay was performed as described previously (38), with some modifications. Briefly, PBMCs were cultured in triplicates on 24-well tissue culture plates (Costar) at $0.5 \times 10^{6}$ 
cells/well in RPMI 1640 medium containing 10\% FBS, $100 \mathrm{U} / \mathrm{ml}$ penicillin, $100 \mu \mathrm{g} / \mathrm{ml}$ streptomycin, and $50 \mu \mathrm{M} \beta$-mercaptoethanol under 3 different culture conditions: unstimulated, using medium only; mitogen-stimulated, using pokeweed mitogen (MP Biochemicals) diluted 1:1,000, fixed Staphylococcus aureus Cowan strain SAC (Sigma-Aldrich) diluted 1:10,000, and $6 \mu \mathrm{g} / \mathrm{ml}$ CpG ODN-2006 (Qiagen-Operon); and mitogen-stimulated (as above) plus $10 \mu \mathrm{g} / \mathrm{ml}$ anti-PD-1 blocking $\mathrm{Ab}$ (clone EH12). Cells were cultured at $37^{\circ} \mathrm{C}$ with $5 \% \mathrm{CO}_{2}$ for 6 days. On day 5 of culture, 96-well ELISpot plates (Millipore) were coated overnight at $4{ }^{\circ} \mathrm{C}$ with affinity-purified goat anti-monkey IgM (10 $\mu \mathrm{g} / \mathrm{ml}$; Rockland Immunochemicals), IgG (10 $\mu \mathrm{g} / \mathrm{ml}$; Rockland Immunochemicals), or $\operatorname{SIV}_{\text {mac239 }} \mathrm{gp} 130(1 \mu \mathrm{g} / \mathrm{ml}$; obtained through the NIH AIDS Research and Reference Reagent Program, Division of AIDS, NIAID, $\mathrm{NIH}$ ). On day 6, ELISpot plates were washed once with PBS-tween and 3 times with PBS, then blocked with RPMI 1640 plus 1\% FBS for 2 hours at $37^{\circ} \mathrm{C}$. Cultured PBMCs were washed twice with RPMI 1640 plus $1 \%$ FBS and transferred to ELISpot plates starting at concentrations of $0.5 \times 10^{6}$ cells/well, followed by 42 -fold serial dilutions on the plates, which were then incubated at $37^{\circ} \mathrm{C}$ for 6 hours. Plates were then washed 3 times with PBS and 3 times with PBS-tween and incubated overnight at $4^{\circ} \mathrm{C}$ with $1 \mu \mathrm{g} / \mathrm{ml}$ biotinconjugated anti-monkey IgM (for detection of total IgM ASCs) or $1 \mu \mathrm{g} / \mathrm{ml}$ anti-monkey IgG (for detection of total IgG and anti-gp130 ASCs) diluted in PBS-tween plus $1 \%$ FBS. Plates were then washed 4 times with PBS-tween and incubated for 1 hour at room temperature with $5 \mu \mathrm{g} / \mathrm{ml} \mathrm{HRP-conjugat-}$ ed Avidin D (Vector laboratories) diluted in PBS-tween plus 1\% FBS. Plates were washed 3 times with PBS-tween plus 1\% FBS and 3 times with PBS and developed using 3-amino-9-ethylcarbazole (Sigma-Aldrich). Following spot development, plates were washed with distilled $\mathrm{H}_{2} \mathrm{O}$ and allowed to dry overnight in the dark. Spots on developed plates were counted using an ELISpot plate reader (Cellular Technology) with ImmunoSpot 3.2 software. Data are presented as number of spots (i.e., ASCs) per $10^{6}$ PBMCs.

In vivo Ab treatment. Cryopreserved samples from a previously described study (19) were analyzed. Briefly, RMs were infused with either partially humanized mouse anti-human PD-1 Ab (clone EH12) or a control Ab (SYNAGIS). Antibodies were administered intravenously at 10 weeks post infection ( $3 \mathrm{mg} / \mathrm{kg}$ body weight) on days $0,3,7$, and 10 .
Viral load measurements. Plasma viral load was determined by quantitative real-time PCR as previously described (19). All viral RNA specimens were extracted and assayed in duplicate, with mean results reported and used in the analyses.

Statistics. Paired Student's $t$ test was used for comparison of responses before and after SIV infection, and 2-sample Student's $t$ test was used to compare differences between groups. Log-transformed data were used when the data were not normal, but log-normal. For nonparametric data, Wilcoxon signed-rank test (for matched-pairs samples) or Wilcoxon ranksum test (for unpaired samples) was used. Pearson's product moment correlation method was used for correlations. The Bonferroni method was used to adjust the $P$ values for multiple comparisons. Statistical analyses were performed using TIBCO Spotfire S+ 8.1. A 2-sided $P$ value less than 0.05 was considered statistically significant.

\section{Acknowledgments}

We thank A. Grakoui, H. Hon, and H. Radziewicz for the Huh7.5 and Huh7.5.PD-L1 cell lines and R. Ahmed for critical input throughout the study. We are grateful to the veterinary staff at the Yerkes Division of Research Resources for their support and H. Drake-Perrow for administrative support. We also thank the Emory CFAR virology core for viral RNA measurements. This work was supported by NIH/National Institute of Allergy and Infectious Diseases grants R01 AI057029, R01 AI074471, and R01 AI071852 to R.R. Amara; Yerkes National Primate Research Center base grant P51 RR00165; and Emory CFAR grants P30 AI050409, R01 AI074417, and P01 AI08080192 to G.J. Freeman.

Received for publication April 8, 2010, and accepted in revised form August 4, 2010.

Address correspondence to: Rama R. Amara, Yerkes National Primate Research Center, Emory University, 954 Gatewood Road, Atlanta, Georgia 30329, USA. Phone: 404.727.8765; Fax: 404.727.7768; E-mail: ramara@emory.edu.
1. Moore RD, Chaisson RE. Natural history of HIV infection in the era of combination antiretroviral therapy. AIDS. 1999;13(14):1933-1942.

2. Sterne JA, et al. Long-term effectiveness of potent antiretroviral therapy in preventing AIDS and death: a prospective cohort study. Lancet. 2005;366(9483):378-384

3. Marthas ML, et al. Viral factors determine progression to AIDS in simian immunodeficiency virus-infected newborn rhesus macaques. J Virol. 1995;69(7):4198-4205.

4. Fauci AS. Host factors and the pathogenesis of HIVinduced disease. Nature. 1996;384(6609):529-534.

5. Brenchley JM, et al. Microbial translocation is a cause of systemic immune activation in chronic HIV infection. Nat Med. 2006;12(12):1365-1371.

6. Giorgi JV, et al. Shorter survival in advanced human immunodeficiency virus type 1 infection is more closely associated with $\mathrm{T}$ lymphocyte activation than with plasma virus burden or virus chemokine coreceptor usage. J Infect Dis. 1999;179(4):859-870.

7. Hazenberg MD, et al. Persistent immune activation in HIV-1 infection is associated with progression to AIDS. AIDS. 2003;17(13):1881-1888.

8. Zhang ZQ, et al. Early depletion of proliferating $B$ cells of germinal center in rapidly progressive simian immunodeficiency virus infection. Virology. 2007;361(2):455-464.

9. Dykhuizen $M$, et al. Determinants of disease in the simian immunodeficiency virus-infected rhesus macaque: characterizing animals with low antibody responses and rapid progression. J Gen Virol. 1998;79(pt 10):2461-2467.

10. De Milito A, Morch C, Sonnerborg A, Chiodi F. Loss of memory (CD27) B lymphocytes in HIV-1 infection. AIDS. 2001;15(8):957-964.

11. Titanji K, et al. Primary HIV-1 infection sets the stage for important B lymphocyte dysfunctions. AIDS. 2005;19(17):1947-1955.

12. Titanji K, et al. Loss of memory B cells impairs maintenance of long-term serologic memory during HIV-1 infection. Blood. 2006;108(5):1580-1587.

13. De Milito A, et al. Mechanisms of hypergammaglobulinemia and impaired antigen-specific humoral immunity in HIV-1 infection. Blood. 2004; 103(6):2180-2186.

14. Peruchon S, et al. Tissue-specific B-cell dysfunction and generalized memory B-cell loss during acute SIV infection. PLoS One. 2009;4(6):e5966.

15. Day CL, et al. PD-1 expression on HIV-specific T cells is associated with T-cell exhaustion and disease progression. Nature. 2006;443(7109):350-354.

16. Petrovas $C$, et al. PD- 1 is a regulator of virus-specific CD8+ T cell survival in HIV infection. J Exp Med. 2006;203(10):2281-2292.

17. Trautmann L, et al. Upregulation of PD-1 expression on HIV-specific CD8+ T cells leads to reversible immune dysfunction. Nat Med. 2006; 12(10):1198-1202.

18. Velu V, et al. Elevated expression levels of inhibitory receptor programmed death 1 on simian immuno- deficiency virus-specific CD8 T cells during chronic infection but not after vaccination. J Virol. 2007; 81(11):5819-5828.

19. Velu V, et al. Enhancing SIV-specific immunity in vivo by PD-1 blockade. Nature. 2009;458(7235):206-210.

20. Nishimura H, Minato N, Nakano T, Honjo T. Immunological studies on PD-1 deficient mice: implication of PD- 1 as a negative regulator for B cell responses. Int Immunol. 1998;10(10):1563-1572.

21. Fecteau JF, Cote G, Neron S. A new memory CD27$\mathrm{IgG}+\mathrm{B}$ cell population in peripheral blood expressing $\mathrm{VH}$ genes with low frequency of somatic mutation. J Immunol. 2006;177(6):3728-3736.

22. Moir S, et al. Evidence for HIV-associated B cell exhaustion in a dysfunctional memory B cell compartment in HIV-infected viremic individuals. J Exp Med. 2008;205(8):1797-1805.

23. Moir S, and Fauci AS. Pathogenic mechanisms of B-lymphocyte dysfunction in HIV disease. J Allergy Clin Immunol. 2008;122(1):12-19; quiz 20-21.

24. Freedman AS, Freeman G, Horowitz JC, Daley J, Nadler LM. B7, a B-cell-restricted antigen that identifies preactivated B cells. J Immunol. 1987; 139(10):3260-3267.

25. Bar-Or A, et al. Immunological memory: contribution of memory B cells expressing costimulatory molecules in the resting state. J Immunol. 2001; 167(10):5669-5677.

26. Ehrhardt GR, Hijikata A, Kitamura H, Ohara O, Wang JY, Cooper MD. Discriminating gene expression profiles of memory B cell subpopulations. 
J Exp Med. 2008;205(8):1807-1817.

27. De Milito A. B lymphocyte dysfunctions in HIV infection. Curr HIV Res. 2004;2(1):11-21.

28. Kuhrt D, et al. Evidence of early B-cell dysregulation in simian immunodeficiency virus infection: rapid depletion of naive and memory B-cell subsets with delayed reconstitution of the naive B-cell population. J Virol. 2010;84(5):2466-2476.

29. Watson $\mathrm{A}$, et al. Plasma viremia in macaques infected with simian immunodeficiency virus: plasma viral load early in infection predicts survival. J Virol. 1997; 71(1):284-290.

30. Brenchley JM, et al. CD4+ $\mathrm{T}$ cell depletion during all stages of HIV disease occurs predominantly in the gastrointestinal tract. J Exp Med. 2004; 200(6):749-759.

31. Okoye A, et al. Progressive CD4+ central memory T cell decline results in $\mathrm{CD} 4+$ effector memory insufficiency and overt disease in chronic SIV infection. J Exp Med. 2007;204(9):2171-2185.

32. Mason RD, Rose RD, Seddiki N, Kelleher AD, Kent SJ. Low pre-infection levels and loss of central memory $\mathrm{CD} 4+\mathrm{T}$ cells may predict rapid progression in SIV-infected pigtail macaques. Virology. 2008; 381(1):11-15.

33. Josenhans C, Suerbaum S. The role of motility as a virulence factor in bacteria. Int J Med Microbiol. 2002; 291(8):605-614.

34. Vijay-Kumar M, Gewirtz AT. Role of flagellin in Crohn's disease: emblematic of the progress and enigmas in understanding inflammatory bowel disease. Inflamm Bowel Dis. 2009;15(5):789-795

35. Petrovas C, et al. SIV-specific CD8+ T cells express high levels of PD1 and cytokines but have impaired proliferative capacity in acute and chronic SIVmac251 infection. Blood. 2007;110(3):928-936.

36. Moir S, et al. Decreased survival of B cells of HIVviremic patients mediated by altered expression of receptors of the TNF superfamily. J Exp Med. 2004; 200(7):587-599.

37. Petrovas $\mathrm{C}$, et al. Differential association of programmed death- 1 and CD57 with ex vivo survival of CD8+ T cells in HIV infection. J Immunol. 2009; 183(2):1120-1132.

38. Crotty S, Aubert RD, Glidewell J, Ahmed R. Tracking human antigen-specific memory $B$ cells: a sensitive and generalized ELISPOT system. J Immunol Methods. 2004;286(1-2):111-122.

39. Rakhmanov M, et al. Circulating CD21low B cells in common variable immunodeficiency resemble tissue homing, innate-like B cells. Proc Natl Acad Sci US A. 2009;106(32):13451-13456.

40. Weiss GE, et al. Atypical memory B cells are greatly expanded in individuals living in a malaria-endemic area. J Immunol. 2009;183(3):2176-2182.

41. Salvato MS, Yin CC, Yagita H, Maeda T, Okumura K, Tikhonov I, Pauza CD. Attenuated disease in SIV-infected macaques treated with a monoclonal antibody against FasL. Clin Dev Immunol. 2007; 2007:93462.

42. Trabattoni D, et al. B7-H1 is up-regulated in HIV infection and is a novel surrogate marker of disease progression. Blood. 2003;101(7):2514-2520.

43. Wang X, et al. B7-H1 up-regulation impairs myeloid DC and correlates with disease progression in chronic HIV-1 infection. Eur J Immunol. 2008; 38(11):3226-3236.

44. Sauce D, et al. PD-1 expression on human CD8 T cells depends on both state of differentiation and activation status. AIDS. 2007;21(15):2005-2013.

45. Okazaki T, Maeda A, Nishimura H, Kurosaki T, Honjo T. PD-1 immunoreceptor inhibits B cell receptor-mediated signaling by recruiting src homology 2-domain-containing tyrosine phosphatase 2 to phosphotyrosine. Proc Natl Acad Sci U S A. 2001;98(24):13866-13871.

46. Morgan D, Mahe C, Mayanja B, Whitworth JA. Progression to symptomatic disease in people infected with HIV-1 in rural Uganda: prospective cohort study. BMJ. 2002;324(7331):193-196.

47. Mehendale SM, et al. Rapid disease progression in human immunodeficiency virus type 1 -infected seroconverters in India. AIDS Res Hum Retroviruses. 2002;18(16):1175-1179.

48. Bentwich Z, Maartens G, Torten D, Lal AA, Lal RB. Concurrent infections and HIV pathogenesis. AIDS. 2000;14(14):2071-2081.

49. Lai L, et al. GM-CSF DNA: an adjuvant for higher avidity IgG, rectal IgA, and increased protection against the acute phase of a SHIV-89.6P challenge by a DNA/MVA immunodeficiency virus vaccine. Virology. 2007;369(1):153-167.

50. Amara RR, et al. Critical role for Env as well as Gag$\mathrm{Pol}$ in control of a simian-human immunodeficiency virus $89.6 \mathrm{P}$ challenge by a DNA prime/recombinant modified vaccinia virus Ankara vaccine. J Virol. 2002;76(12):6138-6146

51. Ziegler TR, et al. Detectable serum flagellin and lipopolysaccharide and upregulated anti-flagellin and lipopolysaccharide immunoglobulins in human short bowel syndrome. Am J Physiol Regul Integr Comp Physiol. 2008;294(2):R402-R410. 